\title{
Metabolomic Response to Huanglongbing: Role of Carboxylic Compounds in Citrus sinensis Response to 'Candidatus Liberibacter asiaticus' and Its Vector, Diaphorina citri
}

\author{
Nabil Killiny ${ }^{1}$ and Yasser Nehela ${ }^{1,2}$ \\ ${ }^{1}$ Department of Plant Pathology, Citrus Research and Education Center, University of Florida, 700 Experiment Station Rd., Lake \\ Alfred 33850, U.S.A.; and ${ }^{2}$ Department of Agricultural Botany, Faculty of Agriculture, Tanta University, Tanta, Egypt
}

Accepted 10 May 2017.

\begin{abstract}
Huanglongbing, a destructive disease of citrus, is caused by the fastidious bacterium 'Candidatus Liberibacter asiaticus' and transmitted by Asian citrus psyllid, Diaphorina citri. The impact of ' $\mathrm{Ca}$. L. asiaticus' infection or $\mathrm{D}$. citri infestation on Valencia sweet orange (Citrus sinensis) leaf metabolites was investigated using gas chromatography mass spectrometry, followed by gene expression analysis for 37 genes involved in jasmonic acid (JA), salicylic acid (SA), and proline-glutamine pathways. The total amino acid abundance increased after ' $\mathrm{Ca}$. L. asiaticus' infection, while the total fatty acids increased dramatically after infestation with $D$. citri, compared with control plants. Seven amino acids (glycine, L-isoleucine, L-phenylalanine, L-proline, L-serine, L-threonine, and L-tryptophan) and five organic acids (benzoic acid, citric acid, fumaric acid, SA, and succinic acid) increased in ' $\mathrm{Ca}$. L. asiaticus'-infected plants. On the other hand, the abundance of trans-JA and its precursor $\alpha$-linolenic increased in $D$. citri-infested plants. Surprisingly, the double attack of both $\mathrm{D}$. citri infestation and ' $\mathrm{Ca}$. L. asiaticus' infection moderated the metabolic changes in all chemical classes studied. In addition, the gene expression analysis supported these results. Based on these findings, we suggest that, although amino acids such as phenylalanine are involved in citrus defense against ' $C a$. L. asiaticus' infection through the activation of an SAmediated pathway, fatty acids, especially $\alpha$-linolenic acid, are involved in defense against $D$. citri infestation via the induction of a JA-mediated pathway.
\end{abstract}

Huanglongbing (HLB), also known as citrus greening disease, is one of the oldest diseases in citrus. Most previous studies suggested that HLB originated in East Asia at the end of 1800s (Bové 2006; da Graça and Korsten 2004; Gottwald 2010; Gottwald et al. 1989). It was described first in Chinese as huanglongbing in 1956 or the "yellow shoot disease" in English (Lin 1956). HLB was detected in São Paulo, Brazil in 2004 and in South Florida (in the United States) in 2005 (Bové 2006; Gottwald 2010; Wang and Trivedi 2013). In August 2005, HLB was first confirmed in south Miami-Dade County, 7 years after the first

Corresponding author: N. Killiny; Telephone: 863-956-8833;

E-mail: nabilkilliny@ufl.edu

*The $\boldsymbol{e}$-Xtra logo stands for "electronic extra" and indicates that two supplementary tables are published online.

@ 2017 The American Phytopathological Society report of its vector in the United States. Since then, HLB has been discovered in Louisiana (in 2008), South Carolina and Georgia (in 2009), and, recently, in Texas and California (in 2012). Additionally, it has been recorded in many Caribbean countries, including Belize, Cuba, Mexico, and Jamaica (Wang and Trivedi 2013).

HLB is one of the most destructive diseases in citrus groves, which threatens citrus production across the world (Bové 2006; da Graça 1991; Gottwald 2010; Wang and Trivedi 2013). Among the most important problems adding to the threat of HLB disease is the delay of disease symptom expression following inoculation. For example, the disease symptoms in young trees may appear as early as 6 months after infection and might take 1 to 5 years to appear on mature trees (Bové 2006; Wang and Trivedi 2013). The characteristic symptoms of HLB are yellow shoots, blotchy-mottled leaves, and stunted shoots; and, in many trees, there is branch dieback and sometimes tree death as the disease progresses (Bové 2006; Wang and Trivedi 2013). In addition, many diseased trees produce misshapen, small, and discolored fruit that are unusable for fresh sale fruit or for processing. (Bové 2006; da Graça and Korsten 2004; Halbert and Manjunath 2004; Wang and Trivedi 2013).

HLB is caused by the plant-pathogenic, phloem-limited, unculturable bacterium 'Candidatus Liberibacter sp.', a member of the gram-negative and $\alpha$-proteobacterium (Bové 2006; Gottwald 2010). Based on the characteristic $16 \mathrm{~S}$ ribosomal DNA sequences, taxonomically, there are three HLBassociated species: ' $\mathrm{Ca}$. L. asiaticus', ' $\mathrm{Ca}$. L. africanus', and 'Ca. L. americanus' (Bové and Ayres 2007; Gottwald 2010; Wang and Trivedi 2013), named for their presumptive origins of Asia, Africa, and the Americas, respectively (Wang and Trivedi 2013). The tree-to-tree transmission of Liberibacter spp. can occur by budwood or citrus psyllid (Hemiptera: Liviidae) insect vectors: the Asian citrus psyllid Diaphorina citri Kuwayama in Asia and America and the African psyllid Trioza erytreae Del Guercio in Africa (Bové 2006; da Graça 1991; Gottwald 2010; Wang and Trivedi 2013). Among the three Liberibacter spp., ' $C a$. L. asiaticus' is the most dominant, causing huge economic losses to citrus production worldwide (Bové 2006; Gottwald 2010). Although HLB affects most, if not all, citrus varieties, certain varieties have been reported to be more resistant than others (Cevallos-Cevallos et al. 2012; Folimonova et al. 2009).

Upon pathogen infection or insect herbivory, plants develop multiple mechanisms of defense response to protect themselves (Durrant and Dong 2004; Fu and Dong 2013; Liechti et al. 
2006). Although many studies have been carried out to understand plant defense responses against biotic stressors, only a few studies about the role of amino acid (AA), organic acid (OA), and fatty acid (FA) pathways in regulating plant defense responses have been reported. Among the many metabolic changes that may occur in stressed plants, changes in AA and OA profiles are clearly reported after biotic stress (L. S. Chen et al. 2009; Malik et al. 2014), as well as abiotic stresses such as zinc deficiency (Cevallos-Cevallos et al. 2011) and water stress (Malik et al. 2014). Previously, many metabolomics-based studies reported that pathogen infection and vector infestation may cause major changes in metabolite composition of citrus (Cevallos-Cevallos et al. 2011; Chin et al. 2014; Malik et al. 2014; Slisz et al. 2012) and potato (Wallis et al. 2012, 2014 , 2015) plants. Changes in AA as a plant response are due to different mechanisms such as the transaction of pathogenesisrelated proteins, the generation of reactive oxygen species (ROS), activation of nonexpressor of pathogenesis-related proteins 1 (NPRl), or induction of salicylic acid (SA) biosynthesis (Durrant and Dong 2004; Rojas et al. 2014).

In plant-pathogen-vector pathosystems, it has been suggested that the role of plant metabolites is to save the energy requirements for plant defense responses; however, more important roles have been reported (Bolton 2009; Kangasjärvi et al. 2012). The changes in plant metabolites might contribute directly to plant defense responses. For example, phenylalanine is the precursor of SA (Rojas et al. 2014). SA is a stressassociated phytohormone, which is implicated in defense response against biotrophic and hemibiotrophic pathogens, and plays an important role in induction of systemic acquired resistance (SAR) (Bari and Jones 2009; Glazebrook 2005; Hatcher et al. 2004). Likewise, $\alpha$-linolenic acid (C18:3) is the precursor of trans-jasmonic acid ( $t \mathrm{JA}$ ) (Tooker and De Moraes 2009; War et al. 2012). $t$ JA is another stress-associated phytohormone, which is involved in defense against insect herbivory and necrotrophic pathogens (Bari and Jones 2009; Glazebrook 2005; Hatcher et al. 2004).

In citrus, defense responses that involve complex metabolic signaling have been described, including AA (CevallosCevallos et al. 2011, 2012; Chin et al. 2014; Malik et al. 2014; Slisz et al. 2012), polyamines (Malik et al. 2014), OA (CevallosCevallos et al. 2011; Slisz et al. 2012), FA (Cevallos-Cevallos et al. 2012; Tooker and De Moraes 2009), phytohormones (Tooker and De Moraes 2009; War et al. 2012), and other secondary metabolites (War et al. 2012). Recently, the vital role of small RNA in plant defense against various pathogens was reported (Seo et al. 2013; Zhao et al. 2013). In citrus, ' $\mathrm{Ca}$. L. asiaticus' increases generation of several microRNA and small interfering RNA, which could be used as diagnostic markers of HLB (Zhao et al. 2013). Nonetheless, the existing defense mechanisms in plants, however advanced, are usually not enough to overcome the harmful effects of the pathogen.

Although many previous studies focused on the changes in citrus metabolites after different stressors, this is the first controlled comparison between healthy, ' $\mathrm{Ca}$. L. asiaticus'-infected, D. citri-infested, and double-attacked 'Valencia' sweet orange plants. We hypothesize that both ' $C a$. L. asiaticus' and $D$. citri may cause metabolic changes in leaves but these changes could be dissimilar under various stressors. In addition, alteration in some metabolite abundance, especially the phytohormonal precursors, could lead directly to greater changes in the stressassociated phytohormone levels. Due to the current inability to culture ' $\mathrm{Ca}$. L. asiaticus', our knowledge about its virulence mechanism is still limited (Wang and Trivedi 2013). We believe that the expanded knowledge about the metabolic changes which occur after infection with ' $C a$. L. asiaticus' could help provide clues for understanding the pathogen's effect on Valencia sweet orange. Therefore, this study is a further step to clarify citrus defense mechanisms against ' $C a$. L. asiaticus' as well as $D$. citri in order to find novel, sustainable management strategies for HLB control.

\section{RESULTS}

Overall, 36 compounds were detected in leaf extracts using gas chromatography mass spectrometry (GC-MS); 22 AA, 9 $\mathrm{OA}$, and $5 \mathrm{FA}$ (Table 1). Of $22 \mathrm{AA}$, there were no significant differences among the treatments for L-aspartic acid, L-cysteine, L-histidine, L-leucine, L-tyrosine, and L-valine. Additionally, three compounds increased (L-threonine, L-tryptophan, and citric acid) and three compounds decreased (L-glutamine, L-lysine, and L-methionine) in all studied treatments without any significant differences among them (Table 1). Although the abundance of total OA were not significantly different between treatments, many important differences were found between individual compounds as well as the subgroups of OA. For total FA, all noncontrol treatments showed significant changes.

\section{' $C a$. L. asiaticus' infection increased the total nonpolar AA abundance, while $D$. citri infestation increased the total nonproteinogenic $\mathrm{AA}$ and total FA abundance.}

The total AA abundance was significantly increased after ' $\mathrm{Ca}$. L. asiaticus' infection $\left(65,084 \pm 2,985 \mathrm{ng} \mathrm{g}^{-1}\right.$ fresh weight [FW]), followed by D. citri-infested (54,540 $\left.\pm 3,254 \mathrm{ng} \mathrm{g}^{-1} \mathrm{FW}\right)$, double-attacked $\left(53,598 \pm 3,844 \mathrm{ng} \mathrm{g}^{-1} \mathrm{FW}\right)$, and controls $\left(47,779 \pm 4,711 \mathrm{ng} \mathrm{g}^{-1} \mathrm{FW}\right)$, but without significant differences between $D$. citri-infested and double-attacked plants (Table 1; Fig. 1A). The total AA category was divided to five groups, depending on their chemical properties, including nonproteinogenic, basic, acidic, polar side chain, and nonpolar side chain AA. Although the ' $\mathrm{Ca}$. L. asiaticus' infection did not affect the total polar AA abundance, it induced the accumulation of total nonpolar AA abundance and decreased both basic and acidic AA compared with the control (Fig. 1B). On the other hand, D. citri infestation induced the accumulation of total FA $\left(10,461 \pm 325 \mu \mathrm{g} \mathrm{g}^{-1} \mathrm{FW}\right)$ and total nonproteinogenic AA $\left(6,979 \pm 792 \mathrm{ng} \mathrm{g}^{-1} \mathrm{FW}\right)$ compared with the control $(5,281 \pm$ $174 \mathrm{\mu g} \mathrm{g}^{-1} \mathrm{FW}$ and 2,617 $\pm 658 \mathrm{ng} \mathrm{g}^{-1} \mathrm{FW}$, respectively) (Fig. 1 $\mathrm{A}$ and $\mathrm{B}$ ). Additionally, both ' $\mathrm{Ca}$. L. asiaticus' infection and $\mathrm{D}$. citri infestation did not affect the total OA. Although ' $\mathrm{Ca}$. L. asiaticus' infection did not change either monocarboxylic or dicarboxylic OA, D. citri infestation reduced the monocarboxylic OA abundance $\left(7,013 \pm 1,042 \mathrm{ng} \mathrm{g}^{-1} \mathrm{FW}\right)$ compared with control plants $\left(10,080 \pm 946 \mathrm{ng} \mathrm{g}^{-1} \mathrm{FW}\right)$ (Fig. 1C).

\section{Infection with ' $\mathrm{Ca}$. L. asiaticus' increased AA abundance in citrus leaves.}

In ' $\mathrm{Ca}$. L. asiaticus'-infected plants, seven compounds increased compared with the control (glycine, L-isoleucine, L-phenylalanine, L-proline, L-serine, L-threonine, and L-tryptophan) and four compounds were decreased (L-glutamic acid, L-glutamine, L-lysine, and L-methionine) (Table 1). L-Proline, the most abundant AA in all treatments, was significantly higher in ' $\mathrm{Ca}$. L. asiaticus'infected leaves $\left(34,549 \pm 2,654 \mathrm{ng} \mathrm{g}^{-1} \mathrm{FW}\right)$ followed by doubleattacked $\left(27,915 \pm 3,788 \mathrm{ng} \mathrm{g}^{-1} \mathrm{FW}\right), D$. citri-infested $(26,230 \pm$ $\left.3,606 \mathrm{ng} \mathrm{g}^{-1} \mathrm{FW}\right)$, and the control $\left(16,910 \pm 2,846 \mathrm{ng} \mathrm{g}^{-1} \mathrm{FW}\right)$ (Table 1). Interestingly, some AA that are phytohormone precursors increased significantly after ' $C a$. L. asiaticus' or D. citri attack. Briefly, L-phenylalanine, the precursor of SA, increased in ' $C a$. L. asiaticus'-infected plants ( $\left.465 \pm 46 \mathrm{ng} \mathrm{g}^{-1} \mathrm{FW}\right)$ compared with the control $\left(361 \pm 88 \mathrm{ng} \mathrm{g}^{-1} \mathrm{FW}\right)$. Furthermore, L-tryptophan, the precursor of auxin, also increased in ' $\mathrm{Ca}$. L. asiaticus'-infected leaves ( $\left.222 \pm 80 \mathrm{ng} \mathrm{g}^{-1} \mathrm{FW}\right)$ compared with the control $\left(47 \pm 26 \mathrm{ng} \mathrm{g}^{-1} \mathrm{FW}\right)$ (Table 1). 
' $C a$. L. asiaticus' infection or $D$. citri infestation altered the $\mathrm{OA}$ profile in citrus leaves.

Nine OA compounds were detected in Valencia sweet orange leaves (Table 1). Although the infection with ' $C a$. L. asiaticus' or infestation with $D$. citri altered the abundance of the nine OA compounds, the total OA abundance remained the same. Although $t$ JA remained at a similar level within the OA profile of ' $\mathrm{Ca}$. L. asiaticus'-infected plants, five OA (benzoic acid [BA], citric acid, fumaric acid, SA, and succinic acid) increased, and three (ferulic acid, malic acid, and quinic acid) decreased significantly (Table 1). On the hand, the OA profile from $D$. citri-infested plants was similar to the control, with the exception of four OA that increased (citric acid, fumaric acid, $t \mathrm{JA}$, and quinic acid) and ferulic acid, which decreased (Table 1). Malic acid, the most abundant OA in all treatments, was significantly lower in ' $\mathrm{Ca}$. L. asiaticus'-infected leaves $\left(17,937 \pm 4,439 \mathrm{ng} \mathrm{g}^{-1} \mathrm{FW}\right)$ compared with the control $\left(39,713 \pm 8,163 \mathrm{ng} \mathrm{g}^{-1} \mathrm{FW}\right)$. BA and SA, which are considered phytohormones, increased in ' $\mathrm{Ca}$. L. asiaticus'-infected plants $\left(5,344 \pm 739\right.$ and $2,521 \pm 646 \mathrm{ng} \mathrm{g}^{-1} \mathrm{FW}$, respectively) compared with the control $\left(2,539 \pm 438\right.$ and $915 \pm 74 \mathrm{ng} \mathrm{g}^{-1}$ $\mathrm{FW}$, respectively). On the other hand, $t \mathrm{JA}$ was significantly higher in $D$. citri-infested leaves $\left(432 \pm 16 \mathrm{ng} \mathrm{g}^{-1} \mathrm{FW}\right)$ followed by double-attacked (356 $\left.\pm 23 \mathrm{ng} \mathrm{g}^{-1} \mathrm{FW}\right)$, ' $C a$. L. asiaticus'-infected $\left(297 \pm 17 \mathrm{ng} \mathrm{g}^{-1} \mathrm{FW}\right)$, and control $(242 \pm$ $11 \mathrm{ng} \mathrm{g}^{-1} \mathrm{FW}$ ) leaves (Table 1).

Table 1. Concentrations of different amino acids (AA), organic acids (OA), and fatty acids (FA) compounds detected in Valencia sweet orange (Citrus sinensis) leaves after the infection with 'Candidatus Liberibacter asiaticus' (CLas) or infestation with Asian citrus psyllid (Diaphorina citri) using gas chromatography mass spectrometry $(n=10)^{\mathrm{y}}$

\begin{tabular}{|c|c|c|c|c|}
\hline \multirow[b]{2}{*}{ Compound } & \multicolumn{4}{|c|}{ Concentration $(\text { mean } \pm \text { standard deviation })^{\mathrm{z}}$} \\
\hline & Control & CLas-infected & D. citri-infested & Double-attacked \\
\hline \multicolumn{5}{|l|}{$\mathrm{AA}\left(\mathrm{ng} \mathrm{g}^{-1} \mathrm{FW}\right)$} \\
\hline \multicolumn{5}{|l|}{ Nonproteinogenic } \\
\hline$\gamma$-Aminobutyric acid & $1,262 \pm 656 \mathrm{c}$ & $3,685 \pm 599 \mathrm{~b}$ & $5,809 \pm 821 \mathrm{a}$ & $4,697 \pm 1,181 b$ \\
\hline L-Pyroglutamic acid & $405 \pm 23 \mathrm{a}$ & $284 \pm 31 \mathrm{bc}$ & $301 \pm 41 b$ & $252 \pm 25 \mathrm{c}$ \\
\hline Tyramine & $950 \pm 73 a$ & $416 \pm 270 b$ & $869 \pm 130 \mathrm{a}$ & $773 \pm 193 a$ \\
\hline \multicolumn{5}{|l|}{ Basic } \\
\hline L-Histidine & $2,453 \pm 100 \mathrm{~ns}$ & $2,315 \pm 233 \mathrm{~ns}$ & $2,356 \pm 216 \mathrm{~ns}$ & $2,350 \pm 135 \mathrm{~ns}$ \\
\hline L-Lysine & $195 \pm 13 a$ & $96 \pm 33 b$ & $105 \pm 27 b$ & $130 \pm 30 b$ \\
\hline \multicolumn{5}{|l|}{ Acidic } \\
\hline L-Aspartic acid & $814 \pm 331 \mathrm{~ns}$ & $642 \pm 136 \mathrm{~ns}$ & $588 \pm 304 \mathrm{~ns}$ & $365 \pm 158 \mathrm{~ns}$ \\
\hline L-Glutamic acid & $3,493 \pm 701 \mathrm{a}$ & $1,268 \pm 276 b$ & $2,681 \pm 215 a$ & $704 \pm 140 b$ \\
\hline \multicolumn{5}{|l|}{ Polar side } \\
\hline L-Asparagine & $10,490 \pm 1,095 \mathrm{a}$ & $8,312 \pm 991 \mathrm{ab}$ & $5,909 \pm 2,987 b$ & $8,284 \pm 1,615 \mathrm{ab}$ \\
\hline L-Cysteine & $24 \pm 5 \mathrm{~ns}$ & $49 \pm 16.68 \mathrm{~ns}$ & $40 \pm 18 \mathrm{~ns}$ & $27 \pm 3 \mathrm{~ns}$ \\
\hline L-Glutamine & $5,442 \pm 2,758 \mathrm{a}$ & $4,014 \pm 1,763 b$ & $4,821 \pm 1,237 b$ & $2,299 \pm 399 b$ \\
\hline L-Serine & $3,215 \pm 1,429 b$ & $6,642 \pm 1,679 a$ & $2,799 \pm 1,974 \mathrm{ab}$ & $2,698 \pm 1,275 \mathrm{ab}$ \\
\hline L-Threonine & $134 \pm 101 b$ & $188 \pm 50 a$ & $149 \pm 67 \mathrm{a}$ & $168 \pm 17 \mathrm{a}$ \\
\hline L-Tyrosine & $354 \pm 57 \mathrm{~ns}$ & $352 \pm 163 \mathrm{~ns}$ & $310 \pm 144 \mathrm{~ns}$ & $387 \pm 35 \mathrm{~ns}$ \\
\hline \multicolumn{5}{|l|}{ Nonpolar side } \\
\hline L-Alanine & $700 \pm 106 b$ & $949 \pm 155 \mathrm{ab}$ & $704 \pm 248 b$ & $1,251 \pm 245 \mathrm{a}$ \\
\hline Glycine & $27 \pm 4 b$ & $63 \pm 11 \mathrm{a}$ & $39 \pm 14 b$ & $38 \pm 9 b$ \\
\hline L-Isoleucine & $67 \pm 12 b$ & $173 \pm 60 a$ & $106 \pm 36 \mathrm{ab}$ & $158 \pm 39 a$ \\
\hline L-Leucine & $65 \pm 6 \mathrm{~ns}$ & $60 \pm 6 \mathrm{~ns}$ & $63 \pm 4 \mathrm{~ns}$ & $59 \pm 4 \mathrm{~ns}$ \\
\hline L-Methionine & $219 \pm 57 \mathrm{a}$ & $183 \pm 26 b$ & $150 \pm 64 b$ & $190 \pm 33 b$ \\
\hline L-Phenylalanine & $361 \pm 88 b$ & $465 \pm 46 \mathrm{a}$ & $186 \pm 73 b$ & $475 \pm 57 \mathrm{a}$ \\
\hline L-Proline & $16,910 \pm 2,846 \mathrm{c}$ & $34,549 \pm 2,654 a$ & $26,230 \pm 3,606 b$ & $27,915 \pm 3,788 b$ \\
\hline L-Tryptophan & $47 \pm 26 b$ & $222 \pm 80 a$ & $206 \pm 111 a$ & $210 \pm 55 a$ \\
\hline L-Valine & $152 \pm 55 \mathrm{~ns}$ & $158 \pm 72 \mathrm{~ns}$ & $121 \pm 59 \mathrm{~ns}$ & $164 \pm 62 \mathrm{~ns}$ \\
\hline Total AA & $47,779 \pm 4,711 \mathrm{c}$ & $65,084 \pm 2,985 a$ & $54,540 \pm 3,254 b$ & $53,598 \pm 3,844 b$ \\
\hline \multicolumn{5}{|l|}{$\mathrm{OA}\left(\mathrm{ng} \mathrm{g}^{-1} \mathrm{FW}\right)$} \\
\hline \multicolumn{5}{|l|}{ Monocarboxylic } \\
\hline Benzoic acid & $2,539 \pm 438 b$ & $5,344 \pm 739 a$ & $2,433 \pm 147 b$ & $4,444 \pm 334 \mathrm{a}$ \\
\hline Ferulic acid & $4,607 \pm 755 a$ & $1,928 \pm 421 b$ & $984 \pm 283 c$ & $1,729 \pm 461 \mathrm{ab}$ \\
\hline$t$-Jasmonic acid & $242 \pm 11 \mathrm{c}$ & $297 \pm 17 \mathrm{c}$ & $432 \pm 16 a$ & $356 \pm 23 b$ \\
\hline Quinic acid & $1,776 \pm 445 b$ & $715 \pm 226 c$ & $2,401 \pm 411 \mathrm{a}$ & $633 \pm 184 c$ \\
\hline Salicylic acid & $915 \pm 74 b$ & $2,521 \pm 646 a$ & $1,363 \pm 298 b$ & $2,345 \pm 485 a$ \\
\hline \multicolumn{5}{|l|}{ Di-carboxylic } \\
\hline Fumaric acid & $4,001 \pm 246 b$ & $6,740 \pm 733 a b$ & $9,119 \pm 642 \mathrm{a}$ & $7,302 \pm 298 \mathrm{a}$ \\
\hline Malic acid & $39,713 \pm 8,163 a$ & $17,937 \pm 4,439 b$ & $33,373 \pm 6,071 \mathrm{ab}$ & $20,741 \pm 4,711 \mathrm{ab}$ \\
\hline Succinic acid & $7,619 \pm 340 \mathrm{c}$ & $17,431 \pm 3,327 \mathrm{ab}$ & $11,486 \pm 2,991 b c$ & $19,465 \pm 3,830 \mathrm{a}$ \\
\hline \multicolumn{5}{|l|}{ Tricarboxylic } \\
\hline Citric acid & $3,859 \pm 396 b$ & $9,574 \pm 715 \mathrm{a}$ & $7,130 \pm 395 \mathrm{a}$ & $7,809 \pm 255 \mathrm{a}$ \\
\hline Total OA & $65,272 \pm 2,214 \mathrm{~ns}$ & $62,487 \pm 8,620 \mathrm{~ns}$ & $68,721 \pm 7,378 \mathrm{~ns}$ & $64,825 \pm 9,420 \mathrm{~ns}$ \\
\hline \multicolumn{5}{|l|}{$\mathrm{FA}\left(\mu \mathrm{g} \mathrm{g}^{-1} \mathrm{FW}\right)$} \\
\hline Linoleic acid (C18:2) & $1,433 \pm 195 \mathrm{c}$ & $2,169 \pm 237 b$ & $3,194 \pm 250 a$ & $2,418 \pm 235 b$ \\
\hline$\alpha$-Linolenic acid (C18:3) & $560 \pm 62 \mathrm{~d}$ & $830 \pm 102 c$ & $1,615 \pm 110 a$ & $1,162 \pm 107 b$ \\
\hline Oleic acid (C18:1) & $1,288 \pm 216 b$ & $1,936 \pm 377 \mathrm{a}$ & $2,422 \pm 322 \mathrm{a}$ & $1,104 \pm 174 b$ \\
\hline Palmitic acid (C16:0) & $1,937 \pm 5 \mathrm{~d}$ & $2,303 \pm 59 \mathrm{c}$ & $2,919 \pm 61 \mathrm{a}$ & $2,496 \pm 85 b$ \\
\hline Stearic acid (C18:0) & $62 \pm 14 \mathrm{c}$ & $202 \pm 42 \mathrm{ab}$ & $312 \pm 83 a$ & $185 \pm 93 b$ \\
\hline Total FA & $5,281 \pm 174 \mathrm{c}$ & $7,440 \pm 169 b$ & $10,461 \pm 325 \mathrm{a}$ & $7,366 \pm 210 b$ \\
\hline
\end{tabular}

${ }^{\mathrm{y}}$ Five biological replicates (two technical replicates for each) were used.

${ }^{\mathrm{z}}$ Different letters indicate statistically significant differences among the studied treatments and "ns" signifies no significant differences between them according to Tukey's honestly significant difference test $(P<0.05)$. 


\section{FA increased upon $D$. citri infestation.}

Five FA were detected in citrus leaves using GC-MS, including palmitic acid (C16:0), stearic acid (C18:0), oleic acid (C18:1), linoleic acid (C18:2), and $\alpha$-linolenic acid (C18:3). All detected FA abundance was higher in D. citri-infested plants compared with other treatments. The concentrations of these FA in ' $\mathrm{C} a$. L. asiaticus'-infected trees and double-attacked trees were higher than in the control but lower than those exposed to D. citri only. Furthermore, no significant differences were observed between ' $C a$. L. asiaticus'-infected plants and double-attacked plants for total FA or linoleic acid. Likewise, no significant differences were observed between ' $\mathrm{Ca}$. L. asiaticus'-infected plants and D. citri-infested trees for oleic acid (Table 1).

Principal component analysis revealed the differences between citrus response to ' $\mathrm{C} a$. $\mathrm{L}$. asiaticus' and its vector.

For the AA, the principal component analysis (PCA) scatter plot shows good discrimination between the four treatments (PC1 and PC2 were 57.4 and 26.6\%, respectively) (Fig. 2A). Furthermore, the associated loading-plot is presented in Figure 2B. Clearly, 11 AA (glycine, L-alanine, L-valine, L-tyrosine, L-isoleucine, L-proline, L-phenylalanine, L-tryptophan, L-threonine, L-cysteine, and L-serine) were positively associated with ' $C a$. L. asiaticus' infection and double-attacked plants.

Likewise, for the OA, the PCA scatter plot (Fig. 2C), and its associated loading-plot (Fig. 2D) were obtained. Good separation between the ' $\mathrm{Ca}$. L. asiaticus'-infected and double- attacked plants (as a group) and both control and D. citriinfested plants (PC1 and PC2 were 57.2, and $21.8 \%$, respectively) is shown in Figure 2C. Additionally, although five OA were positively associated with ' $\mathrm{Ca}$. L. asiaticus' infection (BA, fumaric acid, succinic acid, citric acid, and $\mathrm{SA}$ ), the rest were positively correlated with D. citri infestation (Fig. 2D).

The PCA scatter plot and loading plot of the FA are presented in Figure $2 \mathrm{E}$ and $2 \mathrm{~F}$. Data presented in Figure $2 \mathrm{E}$ provided evidence of well-defined clustering into the four distinct treatment groups with PC1 $(80.2 \%)$ and PC2 (12.5\%). The PCA showed that FA were strongly associated with D. citri infestation (Fig. 2).

For further data analyses, AA were divided chemically into five groups: nonproteinogenic, basic, acidic, polar side chain-, and nonpolar side chain AA. Likewise, OA were divided into three groups: monocarboxylic, di-carboxylic, and tricarboxylic OA. The PCA scatter plot (Fig. 2G) and loadingplot (Fig. 2H) using the total concentration for each group were obtained. Good separation between the ' $\mathrm{Ca}$. L. asiaticus'infected and double-attacked plants (as a group) and both control and D. citri-infested plants (PC1 and PC2 were 38.2, and 23.1\%, respectively) is shown in Figure 2G. Additionally, although monocarboxylic OA, tricarboxylic OA, nonpolar AA, and polar AA were positively associated with ' $\mathrm{Ca}$. L. asiaticus' infection, the FA and nonproteinogenic AA were positively correlated with D. citri herbivory (Fig. 2H).

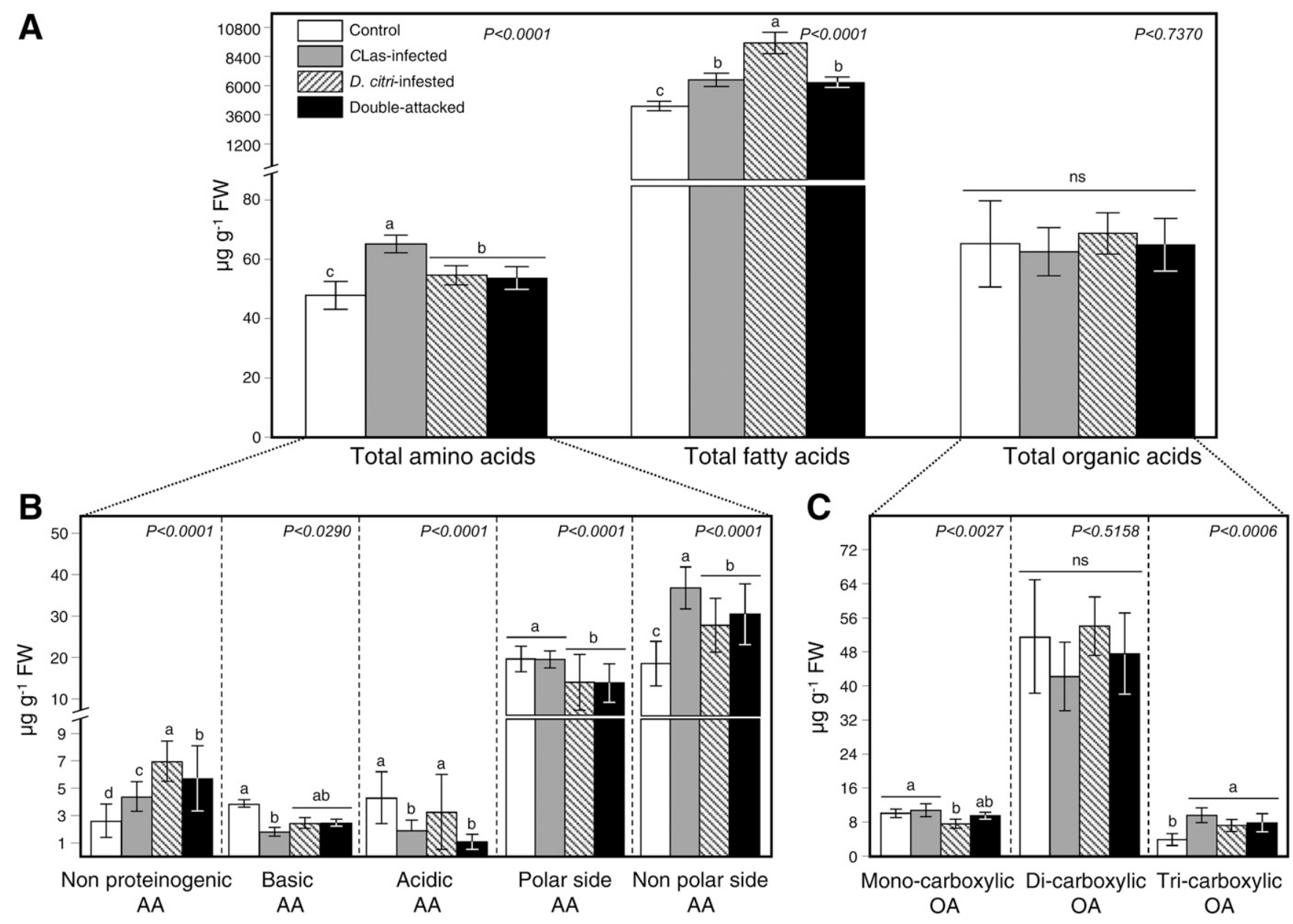

Fig. 1. Concentrations of total amino acid (AA), total fatty acid (FA), and total organic acid (OA) groups detected in Valencia sweet orange (Citrus sinensis) leaves after the infection with 'Candidatus Liberibacter asiaticus' (CLas) or the infestation with Asian citrus psyllid (Diaphorina citri) using gas chromatography mass spectrometry selective ion monitoring mode $(n=10)$. A, Total AA, total FA, and total OA groups; B, different AA groups; and C, different OA groups. All compounds were extracted in methanol and derivatized with methyl chloroformate. Different letters indicate statistically significantly differences among the studied treatments, while "ns" signifies no significant differences between them. 
Three-dimensional surface plot analysis revealed complex interactions among $\mathrm{AA}, \mathrm{OA}$, and FA.

For further understanding of relationships among AA, OA, and FA in Valencia orange leaves, three-dimensional surface plots were obtained (Fig. 3A to L). Generally, the interaction among AA, OA, and FA is complex. Briefly, the effect of FA and OA (as two input parameters) on AA content (as an associated performance metric) was obtained. Unlike the control (Fig. 3A), the total effect of AA content in ' $\mathrm{Ca}$. L. asiaticus'infected plants appeared to be higher in low-FA conditions (Fig. 3B). By contrast, the AA content in D. citri-infested plants appeared to be higher in low-OA conditions and to be lower in
A

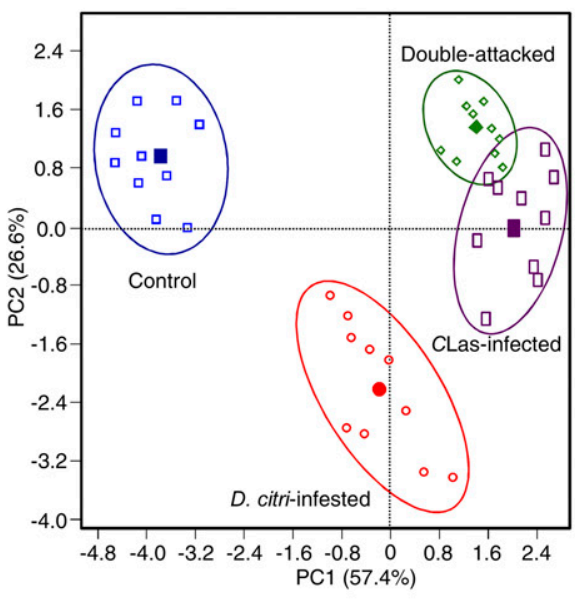

B

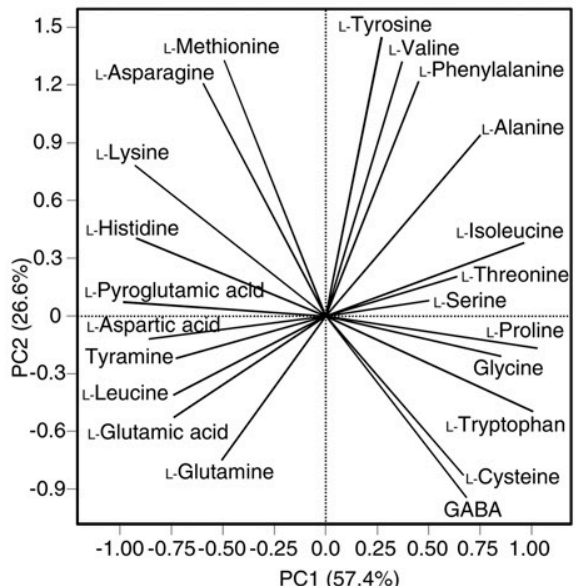

C

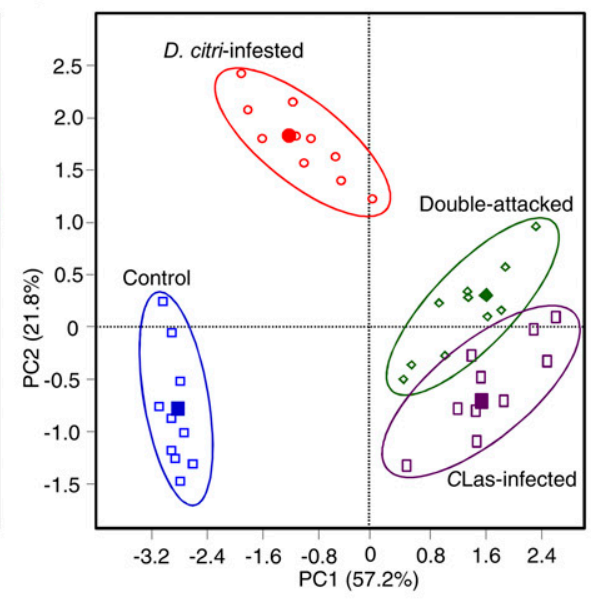

D

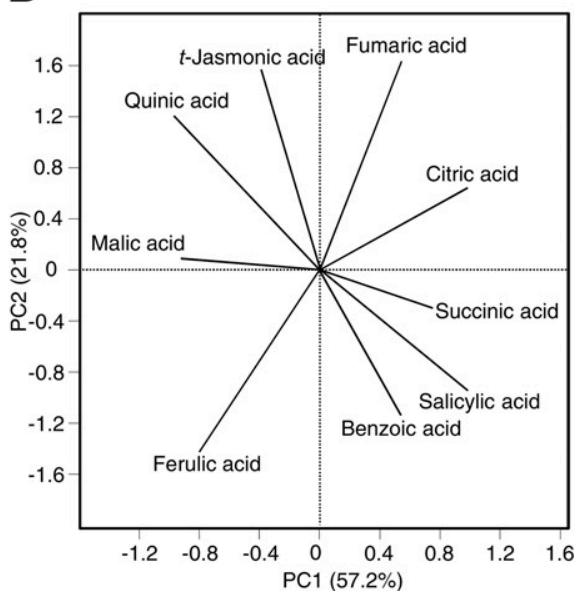

E

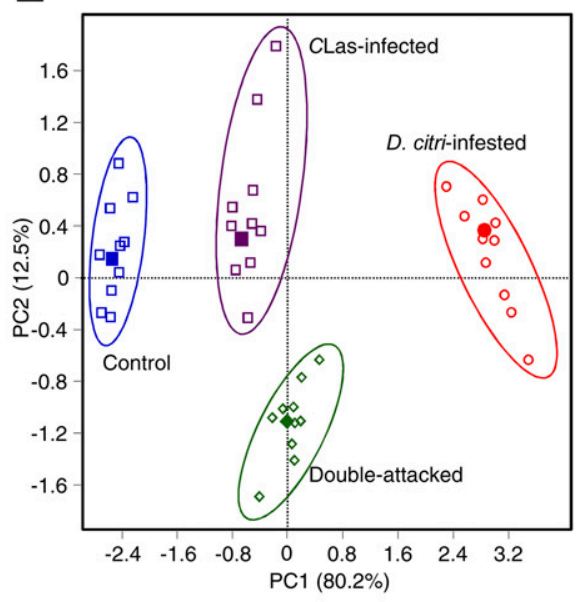

$\mathbf{F}$

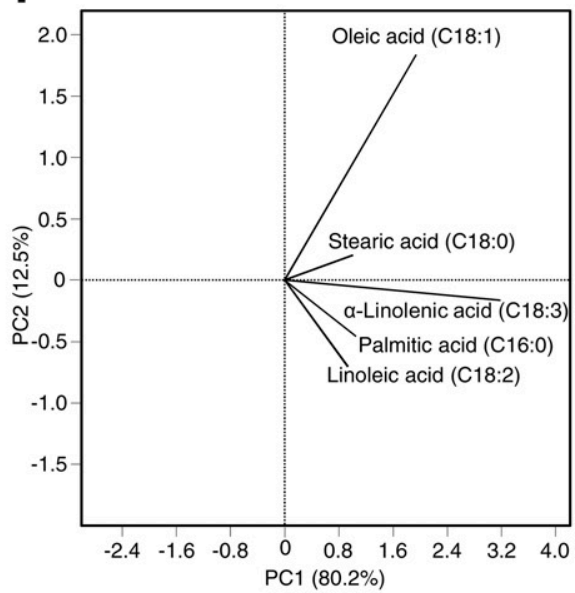

G

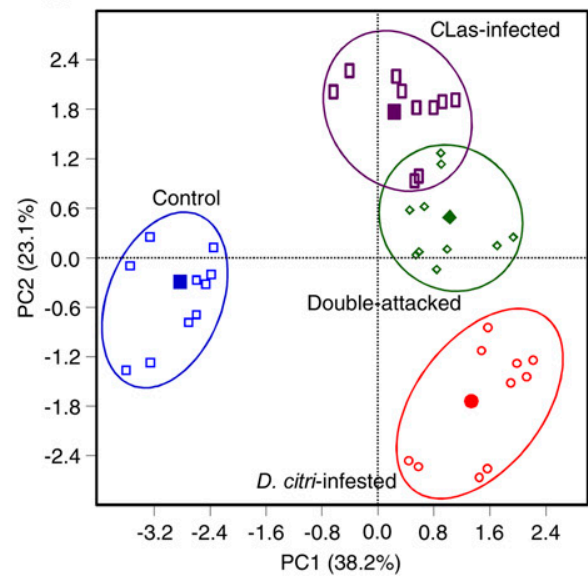

H

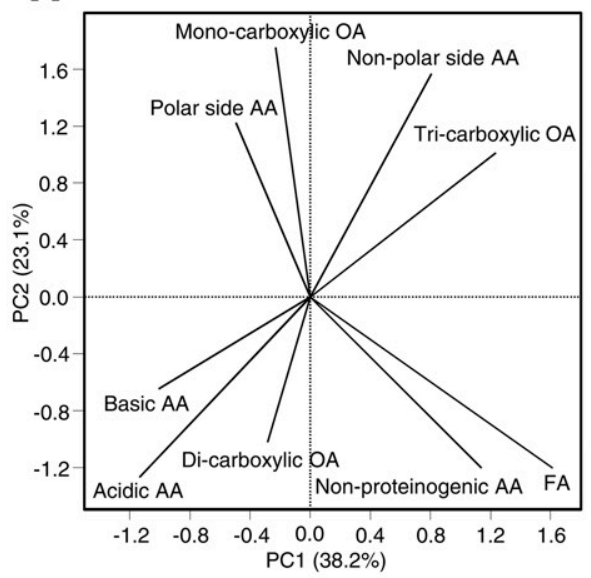

Fig. 2. Principal component analysis (PCA) of different citrus leaves amino acids, organic acids, fatty acids, and total groups detected in Valencia sweet orange (Citrus sinensis) leaves after the infection with 'Candidatus Liberibacter asiaticus' (CLas) or infestation with Diaphorina citri using gas chromatography mass spectrometry $(n=10)$. A, B, and $\mathbf{C}$, PCA scatter plot using the concentrations of the amino acids, organic acids, and fatty acids, respectively. D, E, and $\mathbf{F}$, PCA loading plots using the concentrations of the amino acids, organic acids, and fatty acids, respectively. G, PCA scatter plot using the concentrations of the all carboxylic acids and $\mathbf{H}$, its PCA loading plot. 
high-OA conditions, without any effect on FA content (Fig. 3C). These findings indicate a negative linear relationship between AA and OA content after infestation with $D$. citri. In addition, the total effect of double-attacked plants showed an intermediate effect for ' $C a$. L. asiaticus' infection and $D$. citri herbivory (Fig. 3D).

Likewise, data presented in Figure 3E, F, G, and H demonstrate the effect of FA and AA content (as two input parameters) on OA content (as an associated performance metric) in different treatments. Generally, the total effect of OA was similar to the total effect of AA in all conditions, with the exception of ' $C a$. L. asiaticus'-infected plants, which had a sharp peak (Fig. 3F).

The effect of OA and AA content (as two input parameters) on FA content (as an associated performance metric) is presented in Figure 3I, J, K, and L. Generally, the total effect of FA in ' $C a$. L. asiaticus'-infected, D. citri-infested, and doubleattacked plants was very different compared with the control, which had more flat plateaus. The total effect of FA in ' $\mathrm{Ca}$. L. asiaticus'-infected plants, which had a clear peak, appeared to be lower in high-OA and low-AA conditions (Fig. 3J). Furthermore, the total effect of FA in double-attacked plants was more similar to the total effect of FA in $D$. citri-infested than 'Ca. L. asiaticus'-infected plants (Fig. 3L).

\section{' $C a$. L. asiaticus' and $D$. citri altered the expression} of genes implicated in SA- and JA-mediated pathways.

We investigated the transcript levels of 37 genes involved in biosynthetic pathways of JA (23 genes), SA ( 7 genes), and glutamine-proline metabolism (7 genes) in Valencia sweet orange leaves (Fig. 4). Gene expression data were normalized using four reference genes-elongation factor 1- $\alpha(E F 1)$; F-box/kelch-repeat protein ( $F$-box); glyceraldehyde-3-phosphate dehydrogenase GAPC1, cytosolic (GAPC1, also known as $G A P D H)$; and SAND family protein $(S A N D)$ - which previously showed high stability for transcript normalization in different citrus organs under biotic stress (Mafra et al. 2012; Wei et al. 2014a and b). The normalizing expression levels using the four reference genes were very similar (data not shown). Generally, the expression of all investigated genes increased after infection with ' $C a$. L. asiaticus' or infestation with D. citri. Comparisons of the relative fold changes of the 23 genes involved in the JA pathway, including $\omega-3$ FA desaturase $(C i t F A D)$, linoleate lipoxygenase (CitLOX), allene oxide synthase $(\mathrm{CitAOS})$, allene oxide cyclase (CitAOC), and 12-oxophytodienoate reductase 3 (CitOPR3), are shown as a heat map (Fig. 4A). The gene expression of all involved genes in the JA pathway was upregulated in $D$. citri-infested plants compared with the control (up to 6.5-fold). Additionally, the hierarchical clustering dendrogram (HCD) among treatments showed that ' $\mathrm{Ca}$. L. asiaticus'-infected plants were very similar to the control (dissimilarity distance approximately 1.8), whereas D. citri-infested plants were closer to the double-attacked treatment (dissimilarity distance approximately 5.0) (Fig. 4A). Likewise, HCD among the studied genes represents high similarity in the expression of individual genes, and genes within the same group (CitFAD, CitLOX, CitAOS, CitAOC, and CitOPR3) shared similar patterns and clustered together (Fig. 4A).

On the other hand, phenylalanine ammonia-lyase (CitPAL) and isochorismate synthase (CitICS), which are involved in SA biosynthesis, were highly expressed in ' $\mathrm{Ca}$. L. asiaticus'infected plants (up to 8.0-fold) compared with the control (Fig. 4B). Hierarchical cluster analysis (HCA) among treatments indicated that the double-attacked plants were very similar to ' $\mathrm{Ca}$. L. asiaticus'-infected trees (dissimilarity distance approximately 2.9 ), followed by $D$. citri-infested (dissimilarity distance approximately 6.2) and control trees (dissimilarity distance approximately 10.6). The HCA dendrogram between studied genes also indicated two main clusters: the first cluster was for CitICS (dissimilarity distance approximately 1.7) and the second cluster contained other tested genes (CitPAL; dissimilarity distance approximately 2.4) (Fig. 4B).

Additionally, although proline dehydrogenase $1(\mathrm{CitProDH})$ and $\delta$-1-pyrroline-5-carboxylate dehydrogenase 12A1(CitP5CDH), genes implicated in glutamine and proline metabolism, showed the highest expression levels (4.8- to 6.1-fold) after ' $\mathrm{Ca}$. L. asiaticus' infection, lysine histidine transporter 1(CitLHT1) was highly expressed in double-attacked plants (up to 8.1-fold) (Fig. 4C). Like the SA-biosynthetic genes, the double-attacked plants were very similar to ' $C a$. L. asiaticus'-infected plants (dissimilarity distance approximately 1.8 ), followed by $D$. citri-infested plants (dissimilarity distance approximately 3.1) and the control (dissimilarity distance approximately 11.3). According to these findings, the gene expression results support our findings from the GC-MS work.

\section{DISCUSSION}

In this study, metabolomic analysis of Valencia sweet orange leaves revealed that ' $C a$. L. asiaticus' infection or $D$. citri infestation altered AA, OA, and FA abundance compared with control plants. Most of our results agreed with previous studies on 'Ca. L. asiaticus' (Chin et al. 2014; Malik et al. 2014; Slisz et al. 2012) and were also consistent with results found for ' $\mathrm{Ca}$. L. solanacearum', the pathogen of Zebra chip disease of potato (Wallis et al. 2012, 2014, 2015).

L-Proline was found to be higher in ' $\mathrm{Ca}$. L. asiaticus'infected leaves compared with other treatments and the control. Our findings are in agreement with the previous studies on ' $\mathrm{Ca}$. L. asiaticus'-infected citrus leaves (Cevallos-Cevallos et al. 2011; Rivas et al. 2008), citrus seedlings (Cevallos-Cevallos et al. 2012), potato tubers (Wallis et al. 2012, 2014), and potato leaves (Wallis et al. 2015) but were in contrast to what was found in citrus fruit (Chin et al. 2014; Slisz et al. 2012). The increase in proline might serve to protect the infected plants from ROS (Wallis et al. 2015). In this study, genes involved in proline biosynthesis (CitProDH and CitP5CDH) were upregulated after ' $C a$. L. asiaticus' infection or $D$. citri infestation and positively regulated the generation of ROS (Rojas et al. 2014).

Likewise, the abundance of L-phenylalanine was higher in ' $C a$. L. asiaticus'-infected plants, in agreement with previous studies on citrus (Chin et al. 2014; Slisz et al. 2012) and potato (Wallis et al. 2012, 2014). Previous studies suggested that the higher abundance of L-phenylalanine could be due to the inhibition of the phenylpropenoid biosynthesis pathway by the phytopathogens. Phenylalanine ammonia-lyase $(P A L)$ is the enzyme responsible for converting phenylalanine to cinnamic acid (CA), then to BA and SA (Macarisin et al. 2007; Slisz et al. 2012). Indeed, our findings disagree with this suggestion (Macarisin et al. 2007; Slisz et al. 2012) because BA and SA and their biosynthetic genes (CitPAL and CitICS) increased after infection with ' $\mathrm{Ca}$. L. asiaticus', suggesting that ' $\mathrm{Ca}$. L. asiaticus' cannot suppress the host response by inhibiting $P A L$.

L-Serine and L-threonine abundance was significantly higher in ' $C a$. L. asiaticus'-infected leaves compared with the control, in agreement with previous studies on citrus leaves (CevallosCevallos et al. 2011), citrus fruit (Cevallos-Cevallos et al. 2012), potato tubers (Wallis et al. 2012, 2014), and potato leaves (Wallis et al. 2015). The accumulation of L-serine and L-threonine are commonly associated with biostress responses in plants, mainly due to the increase in photorespiration or overexpression of peptidases and proteases (Cevallos-Cevallos et al. 2012). For example, a serine carboxypeptidase-like gene 

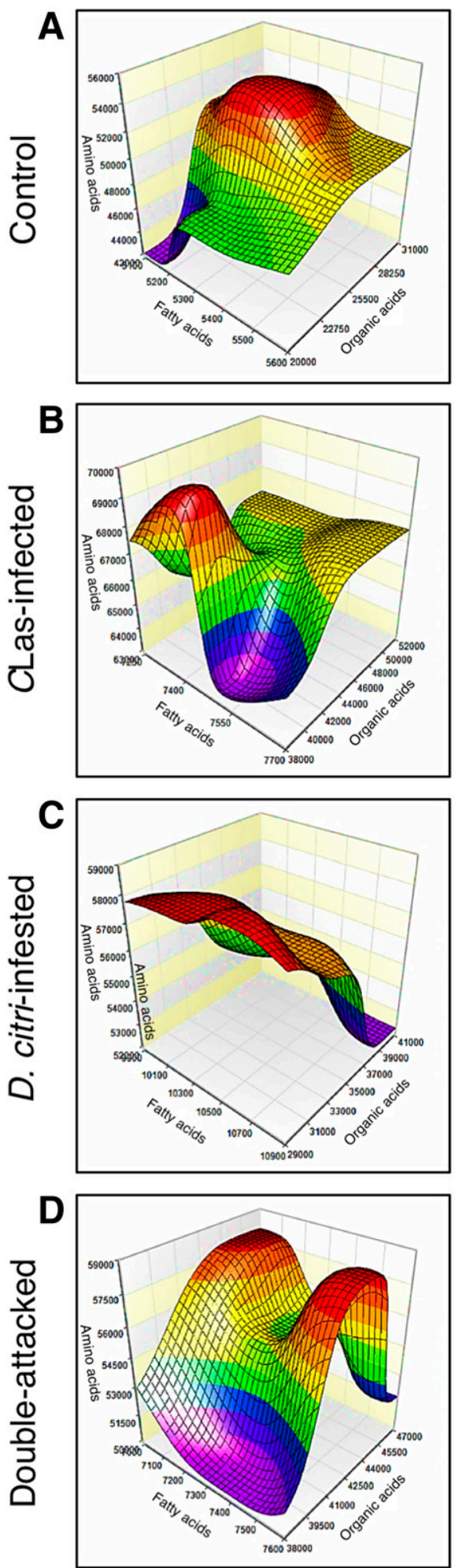

$\mathbf{E}$

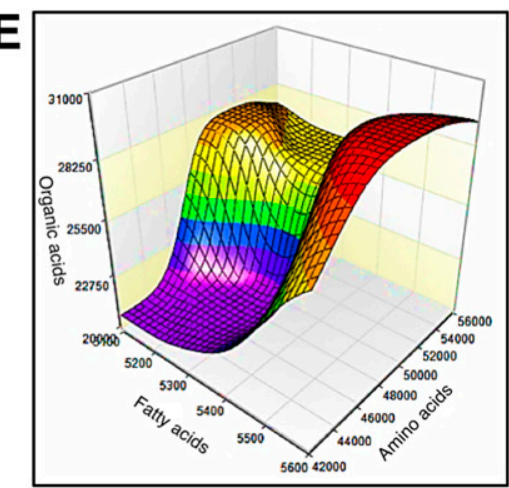

$\mathbf{F}$

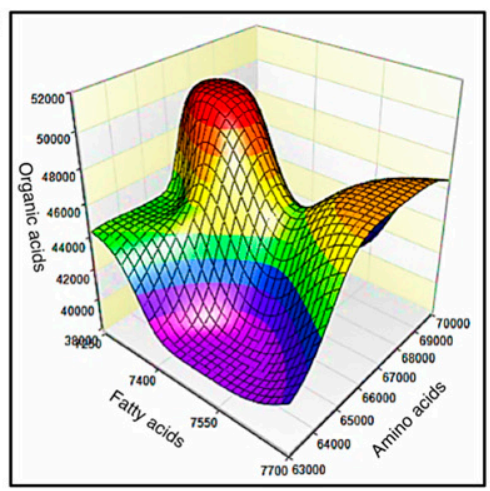

$\mathbf{G}$

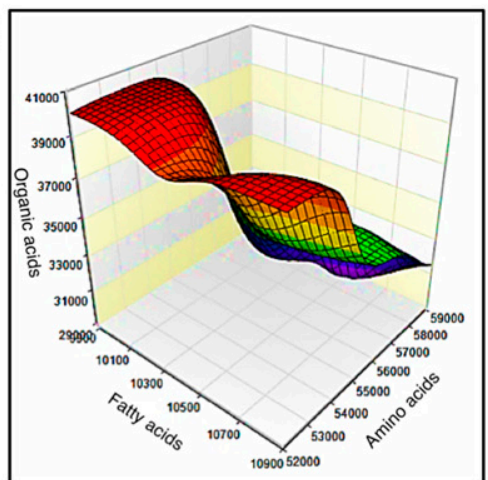

$\mathbf{H}$

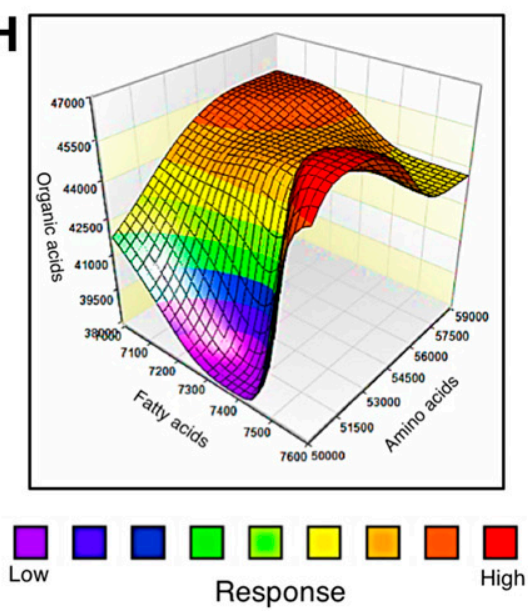

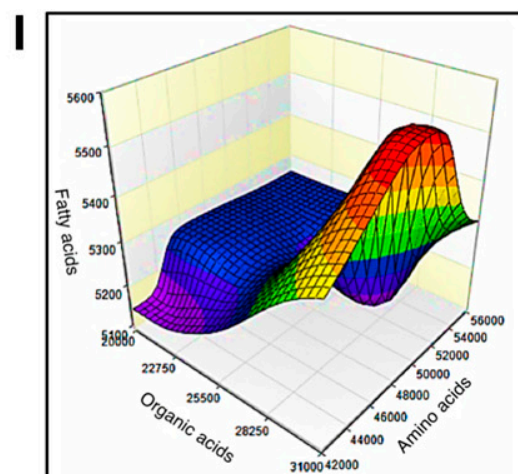

J

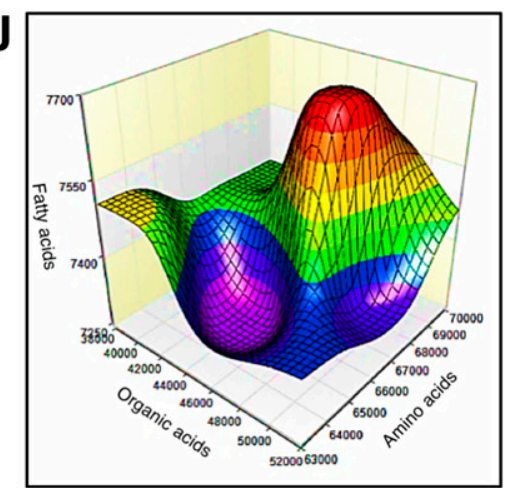

$\mathbf{K}$

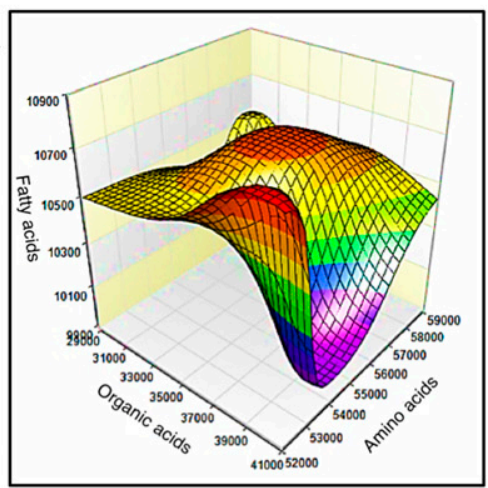

$\mathbf{L}$

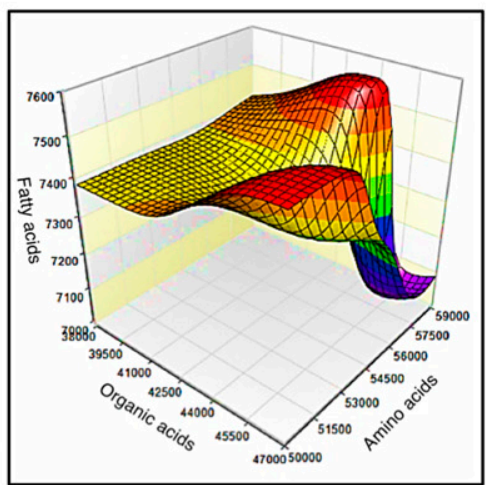

Fig. 3. Three-dimensional surface plots of different citrus leaves amino acid (AA), organic acid (OA), and fatty acid (FA) groups detected in Valencia sweet orange (Citrus sinensis) leaves after the infection with 'Candidatus Liberibacter asiaticus' (CLas) or infestation with Diaphorina citri using gas chromatography mass spectrometry. A, B, C, and D, Effect of FA content, OA content, and their reciprocal interaction on AA content in different treatments. E, F, G, and $\mathbf{H}$, Effect of FA content, AA content, and their reciprocal interaction on OA content in different treatments. I, J, K, and $\mathbf{L}$, Effect of AA content, OA content, and their reciprocal interaction on FA content in different treatments. 
has been found to be upregulated after biotic stress in rice (Liu et al. 2008) and oat (Mugford et al. 2009). Accordingly, the accumulation of serine and threonine suggests that they may play a role in plant defense response against ' $\mathrm{Ca}$. L. asiaticus' and its vector, D. citri (Cevallos-Cevallos et al. 2012; Rojas et al. 2014).

On the other hand, methionine, glutamine, glutamic acid, and lysine were reduced after infection with ' $\mathrm{Ca}$. L. asiaticus'. The reduction of those AA might be due to ' $\mathrm{Ca}$. L. asiaticus' which, being a phloem-restricted bacterium, may utilize these AA, which are found in citrus phloem sap (Hijaz and Killiny 2014), for its growth and reproduction or to inhibit the defense mechanisms of the host plant (Slisz et al. 2012). The Kyoto Encyclopedia of Genes and Genomes online database showed that sequencing of the ' $C a$. L. asiaticus' genome revealed a functional tricarboxylic acid (TCA) cycle, allowing ' $C a$. L. asiaticus' to utilize a wide range of AA such as glutamate, tyrosine, cysteine, histidine, and methionine, in addition to glucose, as energy sources (Duan et al. 2009; Slisz et al. 2012). In addition, the degradation of lysine plays a key role in

A

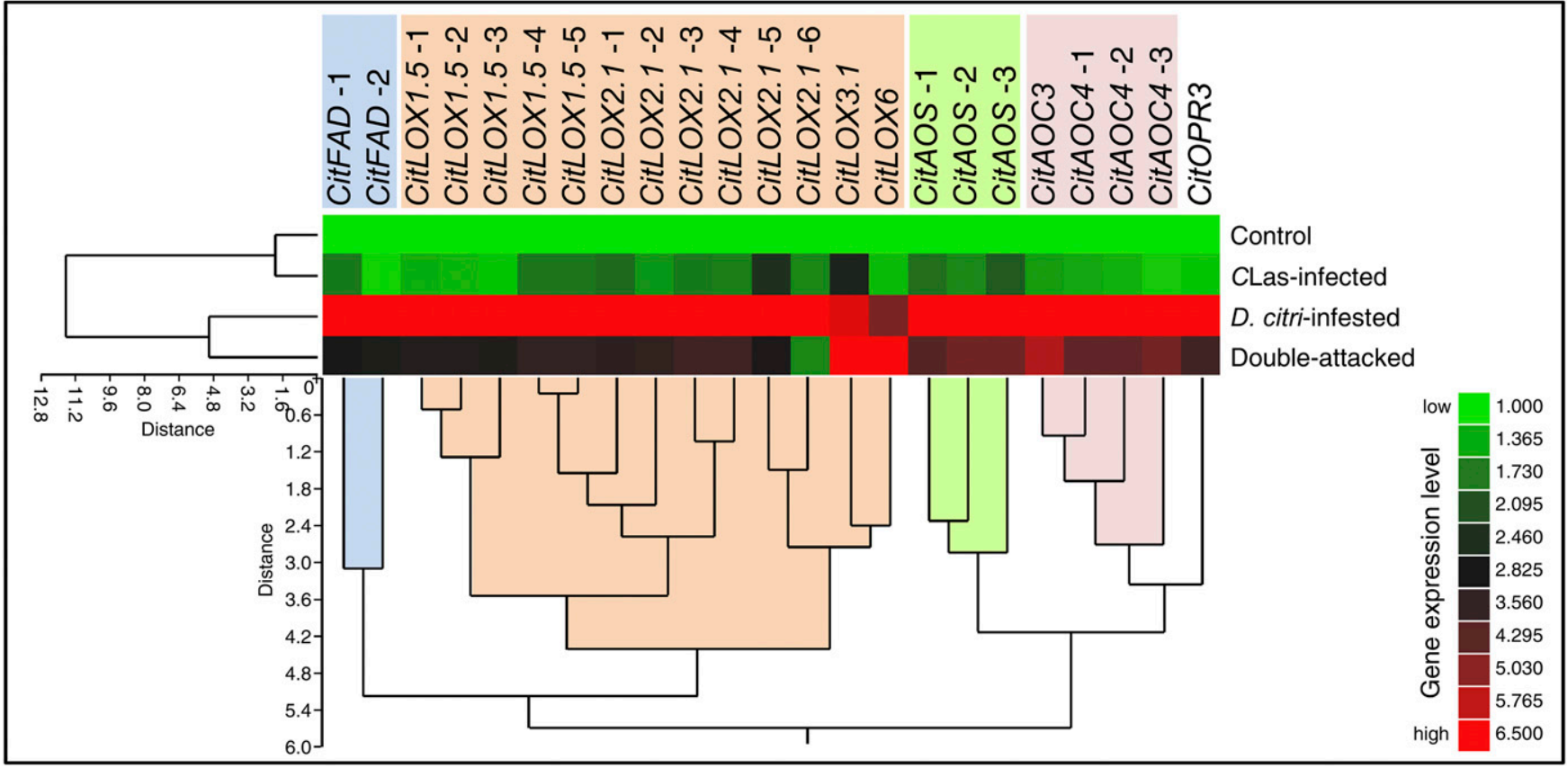

B

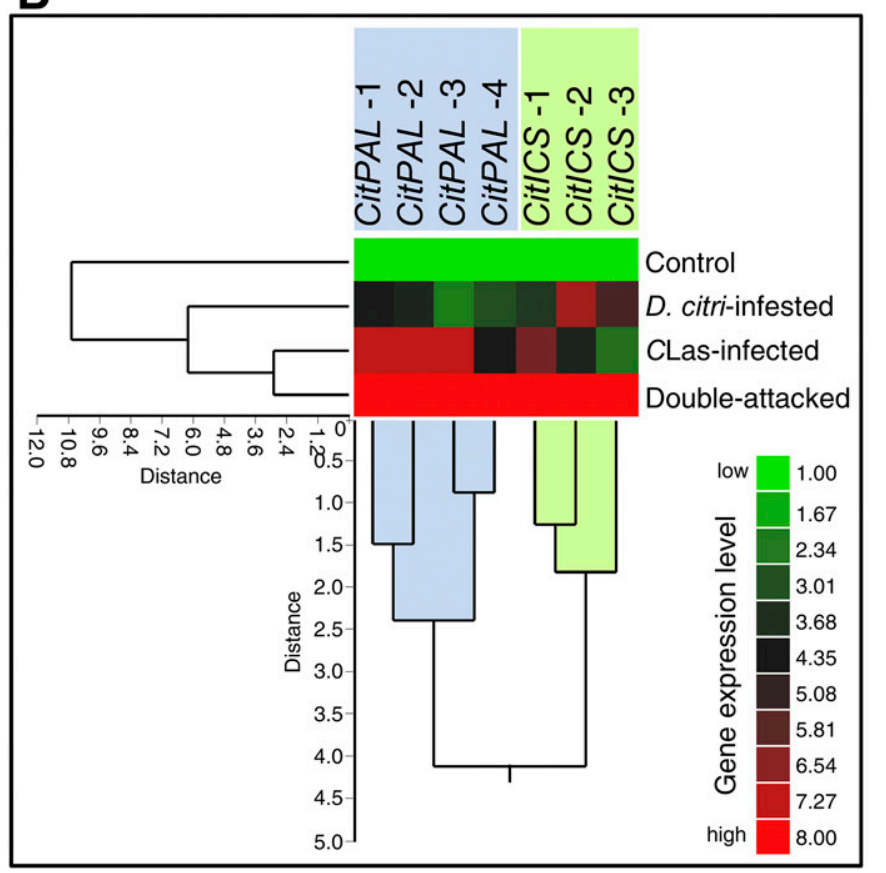

C

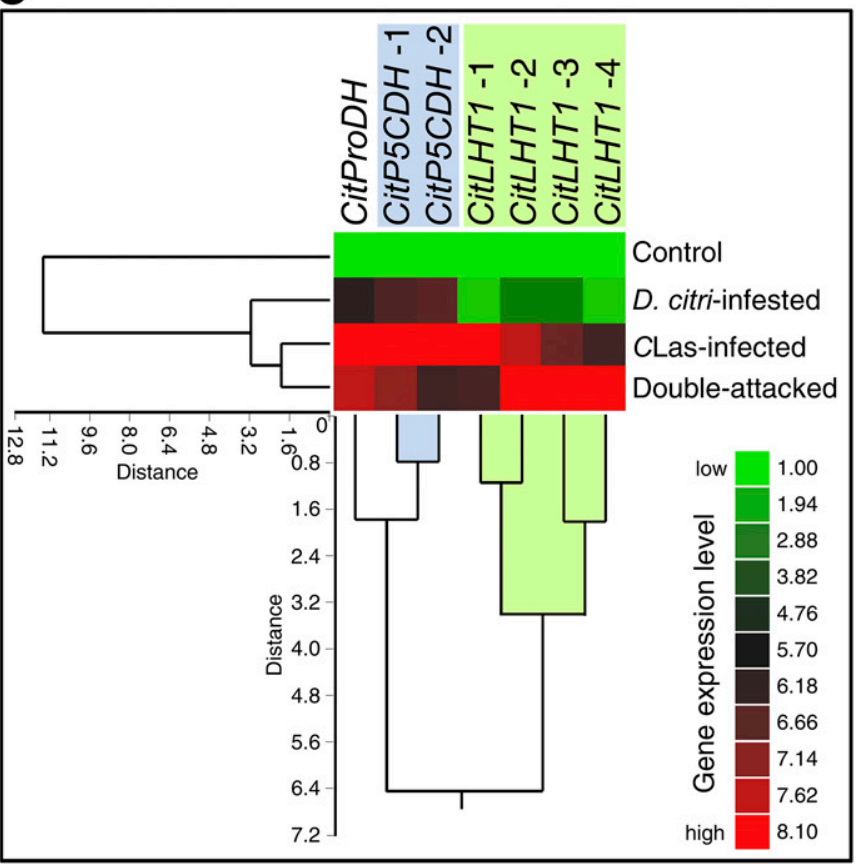

Fig. 4. Heat maps with cluster dendrograms of expressed genes involved in A, jasmonic acid; $\mathbf{B}$, salicylic acid; and $\mathbf{C}$, proline-glutamine pathways in Valencia sweet orange (Citrus sinensis) leaves after the infection with 'Candidatus Liberibacter asiaticus' (CLas) or infestation with Diaphorina citri. Genes are presented in columns and treatments are presented in rows. Treatments and genes are organized using two-way hierarchical cluster analysis based on similarities in auto-scaled values and correlations, respectively. 
activation of SAR (Yang and Ludewig 2014). We suggest that lysine produces pipecolic acid by the activity of the AGD2like defense response protein $1(A L D 1)$, then SA (Yang and Ludewig 2014), to coordinate the SAR via the SA-mediated pathway (Bernsdorff et al. 2016). Many previous studies support our suggestion because the loss of the $A L D 1$ gene reduced the SA abundance and decreased the plant resistance to Pseudomonas syringae in Arabidopsis (Song et al. 2004; Yang and Ludewig 2014).

The reduction of two OA (quinic acid and ferulic acid) is in agreement with previous studies in potato tubers (Wallis et al. 2014, 2015). In addition, previous studies showed that some OA were accumulated in citrus after ' $\mathrm{Ca}$. L. asiaticus' infection, including citrate in leaves and fruit (Cevallos-Cevallos et al. 2011; Slisz et al. 2012) and succinate in fruit (Slisz et al. 2012). The accumulation of TCA-cycle-related OA might be due to the catabolism of some proteinogenic AA (Stipanuk 2006). Generally, glucogenic AA are broken down into pyruvate, $\alpha$-ketoglutarate, succinyl CoA, fumarate, or oxaloacetate, whereas ketogenic AA are broken down into acetoacetate or acetyl-CoA. Finally, $\alpha$-ketoglutarate or oxaloacetate act as the amino group acceptor in all AA catabolism pathways (Forest and Wightman 1972).

Our results showed that the infestation with $D$. citri significantly changed the abundance of several AA in citrus leaves. Briefly, only four AA (L-proline, L-tryptophan, L-serine, and L-threonine) were higher in $D$. citri-infested leaves compared with the control. This is consistent with the previous findings in potato leaves after the feeding of potato psyllid (Bactericera cockerelli) (Yang et al. 2011), and in D. citri-infested citrus leaves (Malik et al. 2014). The observed proline accumulation in this study could be injury induced by $D$. citri feeding because a higher abundance of proline also was observed in potato foliage attacked by the Colorado potato beetle (Leptinotarsa decemlineata) and potato leafhopper (Empoasca fabae) (Tomlin and Sears 1992). Additionally, insect feeding could induce senescence of leaves, and a correlation between serine abundance and senescence of leaves was reported (Malik 1982; Yang et al. 2011), explaining the higher abundance of serine found in D. citri-infested leaves.

Moreover, four AA were decreased in D. citri-infested leaves, including L-methionine, L-asparagine, L-glutamine, and L-lysine. This is in agreement with previous studies, which showed a significant reduction in asparagine, glutamate, and lysine (Malik et al. 2014; Yang et al. 2011). The reduction of glutamate and aspartate abundance could partially be a result of D. citri feeding. As a phloem-feeding insect, D. citri consumes large amounts of glutamate and aspartate from the host plants (Douglas 1993; Yang et al. 2011). Another reason for glutamate and aspartate reduction could be due to their conversion into AA (Yang et al. 2011). For example, lysine could be synthesized from aspartate (Matthews and Hughes 1993). Therefore, the lysine reduction in this study may be due to the decrease in the available aspartate for lysine synthesis (Yang et al. 2011). As another example, proline is synthesized from glutamate and arginine (Boggess 1976; Malik et al. 2014). Therefore, in this study, the lower concentrations of glutamate found in D. citriinfested leaves could be partially due to its conversion to proline (Boggess 1976; Yang et al. 2011).

Interestingly, $D$. citri strongly influenced the linoleic acid and $\alpha$-linolenic acid abundance in $D$. citri-infested leaves. This is in agreement with previous studies on different herbivores and different hosts, including the gall-inducing caterpillars Gnorimoschema gallaesolidaginis and Heliothis virescens on Solidago altissima stems and leaves (Tooker and De Moraes 2009) and the Hessian fly Mayetiola destructor on rice and wheat (Zhu et al. 2011). $\alpha$-Linolenic acid is strongly associated with chloroplasts and tends to be lower in weakly photosynthetic or nonphotosynthetic leaves (del Río-Celestino et al. 2008). Prior studies showed that linoleic acid and $\alpha$-linolenic acid could be synthesized de novo by some insect species to satisfy their need for these compounds (Buckner and Hagen 2003). Furthermore, citrus plants themselves might induce FA biosynthesis to activate the JA-mediated pathway.

FA and their metabolites, including 12-oxophytodienoic acid (OPDA), JA, and methyl jasmonate, could induce plant defense responses against herbivory (Farmer and Ryan 1992; Tooker and De Moraes 2009; Zeier 2013). JA, which appears to be in higher abundance in D. citri-infested plants in this study, has a key role in plant defense against herbivore attack (herbivore antifeedants) (Bennett and Wallsgrove 1994; Shivaji et al. 2010; Zeier 2013). Also, large numbers of plant mechanisms involved in defense against herbivores are regulated by JA, including antioxidative enzymes, proteinase inhibitors, volatile organic compounds, alkaloid production, and secretion of extrafloral nectar (Bennett and Wallsgrove 1994; Shivaji et al. 2010; War et al. 2012).

Based on those findings, a hypothetical model of AA, OA, and FA and their roles in citrus response is presented in Figure 5. Multiple signaling carboxy molecules are involved in citrus response to ' $C a$. L. asiaticus' infection or $D$. citri infestation through three major pathways: (i) induction of an SA-mediated pathway, which is associated with the defense response for biotrophic pathogens (Bari and Jones 2009; Glazebrook 2005; Hatcher et al. 2004) such as ' $\mathrm{Ca}$. L. asiaticus'; (ii) induction a JA-mediated pathway, which is associated with defense against insects herbivory of insect such as D. citri (Bari and Jones 2009; Lazebnik et al. 2014; Robert-Seilaniantz et al. 2007); and (iii) induction of a glutamine-proline pathway, which is implicated in ROS generation (Fig. 5).

The SA-mediated pathway (I) could be induced by the pathogen-associated molecular patterns (PAMP) or damageassociated molecular patterns (DAMP), which are triggered by the pathogen (Erb et al. 2012; Kushalappa and Gunnaiah 2013). PAMP or DAMP are perceived by pattern recognition receptors and lead to pattern-triggered immunity (Erb et al. 2012; Kushalappa and Gunnaiah 2013). The higher abundance of SA might be delivered by two different routes. The first route starts by conversion of phenylalanine to CA by the activity of $P A L$ (Z. Chen et al. 2009; Guidetti-Gonzalez et al. 2007), then to SA by benzoic acid-2-hydroxylase $(B A 2 H)$ through BA (Coquoz et al. 1998; Dong et al. 2014). The second route for SA biosynthesis is from isochorismate by the activity of isochorismate synthase $(I C S)$, then isochorismate pyruvate lyase (IPL) (Z. Chen et al. 2009). Both $P A L$ and ICS were expressed at higher levels in ' $C a$. L. asiaticus'-infected plants but there is no evidence for the existence of either $B A 2 H$ or $I P L$ in citrus, particularly because they were not found in the CitEST database (Guidetti-Gonzalez et al. 2007). Additionally, the SA-mediated pathway could be induced by pipecolic acid (Bernsdorff et al. 2016) and hypersensitive reaction (HR) (Guidetti-Gonzalez et al. 2007; Zhao et al. 2005).

Induction of the JA-mediated pathway (pathway ii) is thought to be related to mitogen-activated protein kinase and herbivore-associated molecular patterns. In citrus, these may be triggered by $D$. citri infestation and lead to herbivore-triggered immunity (Erb et al. 2012), thereby inducing the accumulation of $\alpha$-linolenic acid and leading to increased JA abundance (Fig. 5). In the chloroplast, chewing of plant leaves by insects causes the deoxygenation of linoleic acid and $\alpha$-linolenic acid at C9 or C13 by specific lipoxygenase (LOX) pathways to form (9S)- or (13S)-hydroperoxy-octadecadi(tri)enoic acids, which are converted into OPDA. Then, OPDA is transferred to the peroxisome and reduced to JA by 12-oxophytodienoate reductase 3 
(OPR3) (War et al. 2012). In this study, the expression of the enzymes involved in JA biosynthesis was upregulated after $D$. citri infestation. These enzymes include serine palmitoyl transferase (SPT), suppressor of SA-insensitivity 2 (SSI2), $\omega-3$ FA desaturase 7 (FAD7), $\omega$-3 FA desaturase 8 (FAD8), LOX, allene oxide synthase $(A O S)$, allene oxide cyclase $(A O C)$, and OPR3 (Kachroo et al. 2003; Wasternack and Hause 2013). In agreement with our findings, a previous iTRAQ proteome and transcriptome study showed that the LOX protein was upregulated in ' $\mathrm{Ca}$. L. asiaticus'-infected sweet orange plants

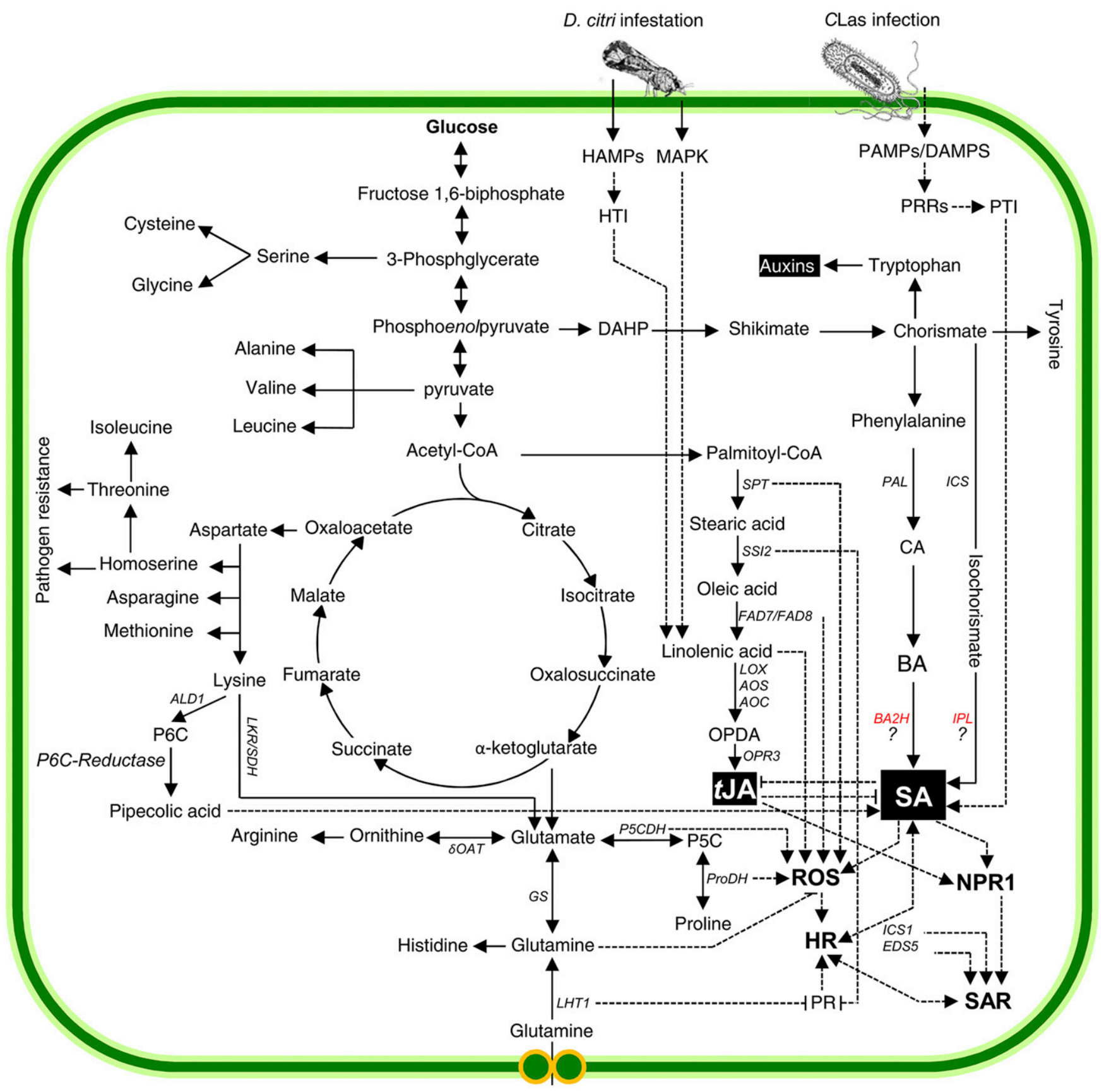

Fig. 5. Schematic representation of amino acids, organic acids, and fatty acids biosynthesis and their roles in citrus response to 'Candidatus Liberibacter asiaticus' (CLas) infection or Diaphorina citri attack. As a generalized model, multiple signaling carboxy molecules participate in Valencia orange response against ' $C a$. L. asiaticus' infection or $D$. citri infestation through three major pathways. (i) Induction of salicylic acid (SA)-mediated pathway using phenylalanine, which is mainly associated with defense response for biotrophic pathogens such as ' $\mathrm{Ca}$. L. asiaticus'. (ii) Induction of jasmonic acid (JA)mediated pathway, which is associated with defense against insect herbivory such as D. citri. Induction of the JA-mediated pathway is thought to be related to the accumulation of $\alpha$-linolenic acid. The interaction between SA- and JA-mediated pathways is controversial. The interaction may be antagonistic or synergistic. Both SA and JA play important roles in the generation of reactive oxygen species (ROS) and the establishment of systemic acquired resistance (SAR) during the activation of nonexpressor of pathogenesis-related proteins 1 (NPR1). (iii) Activation of the glutamine-proline pathway, which is implicated in ROS generation due to the activity of proline dehydrogenase (ProDH) and $\delta$ 1-pyrroline-5-carboxylate dehydrogenase (P5CDH). Solid lines represent the amino acid, organic acid, and fatty acid metabolic pathways and dashed lines represent hypothetical mechanisms of response pathways in Valencia sweet orange; arrows indicate positive reaction while blunt-ended lines indicate negative regulation or unknown reaction. Abbreviations: HAMP $=$ herbivoreassociated molecular patterns, MAPK $=$ mitogen-activated protein kinase, PAMP $=$ pathogen-associated molecular patterns, DAMP $=$ damage-associated molecular patterns, $\mathrm{HTI}=$ herbivore-triggered immunity, $\mathrm{PRR}=$ pattern recognition receptors, $\mathrm{PTI}=$ pattern-triggered immunity, $\mathrm{CA}=$ cinnamic acid, $\mathrm{BA}=$ benzoic acid, $t \mathrm{JA}=$ trans-JA, and $\mathrm{HR}=$ hypersensitive reaction . 
compared with the control (Fan et al. 2011). Both SA and JA play important roles in the generation of ROS and the induction of SAR during the activation of NPRl (Liechti et al. 2006; Rojas et al. 2014; Zhang et al. 2015).

Induction of the glutamine-proline pathway (pathway iii) is implicated in ROS generation due to the activity of proline dehydrogenase $(\mathrm{ProDH})$ and $\delta$ 1-pyrroline-5-carboxylate dehydrogenase $(P 5 C D H)$ (Rojas et al. 2014). In addition, the high activities of SPT and FAD7 or FAD 8 and the increase in the abundance of $\alpha$-linolenic acid suggested that they play key roles in accumulation of ROS, which lead to HR (Rojas et al. 2014). HR and SAR are often associated together in infected plant tissues (Kombrink and Schmelzer 2001).

Based on those findings, we tried to understand how ' $\mathrm{Ca}$. L. asiaticus' or D. citri reconfigure the host plant metabolism. We reported potential changes in orange leaf physiology after ' $\mathrm{Ca}$. L. asiaticus' infection or $D$. citri infestation, including particular alterations in AA, OA, FA, and gene expression. These changes could be implicated directly or indirectly in the expression of plant defense-related genes against ' $\mathrm{Ca}$. L. asiaticus' or D. citri. Finally, understanding and analyzing the variation in citrus physiology after ' $C a$. L. asiaticus' infection or $D$. citri infestation could lead to a comprehensive picture of defense responses to ' $C a$. L. asiaticus' and its vector, $D$. citri, in Valencia sweet orange and perhaps other citrus. Further studies are needed to examine the relationships between metabolomic changes, defense-related mechanisms, and regulation of host genes.

\section{MATERIALS AND METHODS}

Plant materials and growth conditions.

C. sinensis (L.) Osbeck (Valencia sweet orange) was used as the source of plant materials in this study. All trees were approximately $80 \pm 5 \mathrm{~cm}$ tall, approximately 18 months old, and maintained in a United States Department of AgricultureAnimal and Plant Health Inspection Service/Center for Disease Control-approved secured greenhouse at $28 \pm 3^{\circ} \mathrm{C}, 65 \pm 5 \%$ relative humidity, and a photocycle of $16 \mathrm{~h}$ of light and $8 \mathrm{~h}$ or darkness at the Citrus Research and Education Center, University of Florida, Lake Alfred. Weekly, plants were irrigated twice and fertilized once using 20-10-20 NPK fertilizer (Peter's fertilizer, Allentown, PA, U.S.A.). In this study, four treatments (five biological replicates, two technical replicates for each; $n=$ 10) included the following trees tested: (i) control, (ii) ' $C a$. L. asiaticus' infected, (iii) D. citri infested, and (iv) double attacked (' $\mathrm{Ca}$. L. asiaticus'-infected and $\mathrm{D}$. citri-infested). To obtain the ' $\mathrm{Ca}$. L. asiaticus'-infected trees, 10-month-old HLBfree Valencia sweet orange trees were graft inoculated with budwoods from a polymerase chain reaction (PCR)-positive HLB source (HLB-infected Valencia sweet orange trees) and maintained in the same conditions described above. Upon initial symptom development, approximately 7 months later, the infection with ' $C a$. L. asiaticus' was confirmed by PCR (Tatineni et al. 2008). To obtain both D. citri-infested and double-attacked plants, healthy $D$. citri adults (previously reared on Bergera koenegii, nonhost for ' $\mathrm{Ca}$. L. asiaticus') were transferred to 16-month-old healthy or ' $\mathrm{Ca}$. L. asiaticus'infected Valencia sweet orange plants with new flushes (100 insects/tree), caged individually using insect-rearing cages (60 by 60 by $90 \mathrm{~cm}$ ), and maintained in the growth room under the same conditions as described above. One month later, both D. citri-infested and double-attacked plants were cleared of all D. citri nymphs and adults. For sampling, three symptomatic leaves were collected per tree from different positions and different ages; a juvenile leaf from the top, a moderate-aged one from the middle, and a mature leaf from the lower part of the plant. The collected leaves were chopped, mixed together, and immediately kept on ice. Plant materials were kept at $-80^{\circ} \mathrm{C}$ until analysis.

\section{Extraction of citrus leaf metabolites.}

Citrus leaf AA, OA, and FA were extracted from frozen tissue as follows. Briefly, approximately $100 \mathrm{mg}$ of leaf tissue was ground to a fine powder using liquid nitrogen and transferred to a 1.5-ml centrifuge tube. Solvent $(750 \mu \mathrm{l}$ of methanol/water/HCl $6 \mathrm{~N}, 80: 19.9: 0.1$ [vol/vol/vol]) was added to the samples and vortexed for $30 \mathrm{~s}$; next, samples were kept on ice for $10 \mathrm{~min}$, then centrifuged at $1,428 \times g$ for $5 \mathrm{~min}$ at $5^{\circ} \mathrm{C}$. All of the supernatant was transferred to a new 2-ml tube. The extraction was repeated twice more and the supernatant was combined. The collected supernatant was concentrated to $50 \mu \mathrm{l}$ under a nitrogen stream and stored at $-80^{\circ} \mathrm{C}$ for further work.

\section{Methyl chloroformate (MCF) derivatization of $\mathrm{AA}, \mathrm{OA}$, and FA.}

Before derivatization, each sample was spiked with a 5- $\mu$ l aliquot heptadecanoic acid, which is not found in citrus leaves, at $200 \mathrm{ppm}$ as an internal standard. Acidic compounds (AA, $\mathrm{OA}$, and FA) were derivatized with MCF, as described by Hijaz and Killiny (2014), with slight modification. Briefly, $50 \mu \mathrm{l}$ of the methanol extract was transferred to a 1-ml silanized conical microliter insert (Wheaton, Millville, NJ, U.S.A.) and mixed with $180 \mu \mathrm{l}$ of sodium hydroxide $(\mathrm{NaOH}, 1 \mathrm{~N})$. Then, the alkaline mixture was mixed with $170 \mu \mathrm{l}$ of methanol and $34 \mu \mathrm{l}$ of pyridine $(5: 1)$ and vortexed for $10 \mathrm{~s}$. MCF $(20 \mu \mathrm{l})$ was added and vortexed again for $30 \mathrm{~s}$ (twice). Chloroform $(50 \mu \mathrm{l})$ was added with vortexing for $10 \mathrm{~s}$, followed by $200 \mu \mathrm{l}$ of sodium bicarbonate $(50 \mathrm{mM})$ with vigorous mixing for $10 \mathrm{~s}$. After discarding the upper layer, approximately $40 \mu \mathrm{l}$ of the organic layer was transferred to a new insert tube. Then, sodium sulfate (a few milligrams $=$ two to three crystals) was added to dry the organic layer. For GC-MS analysis, $1 \mu \mathrm{l}$ was injected in the scan mode for AA, OA, and FA analysis.

\section{GC-MS analyses.}

All derivatized samples and standards were analyzed using an Autosystem XL GC-MS system (Perkin Elmer, Waltham, MA, U.S.A.) fitted with a ZB-5MS capillary GC column (5\% phenyl-arylene $95 \%$ dimethylpolysiloxane; low bleed, $30 \mathrm{~m}$ by $0.25 \mathrm{~mm}$ by $0.25 \mu \mathrm{m}$ film thickness; Phenomenex, Torrance, CA, U.S.A.). Hydrogen gas was used as the carrier, with a flow rate of $1 \mathrm{ml} / \mathrm{min}$. The GC temperature program was as follows: initial temperature was held at $70^{\circ} \mathrm{C}$ for $4 \mathrm{~min}$, then increased to $280^{\circ} \mathrm{C}$ at a rate of $10^{\circ} \mathrm{C} / \mathrm{min}$, and held for $5 \mathrm{~min}$. The injector and the MS detector temperatures were set at 250 and $180^{\circ} \mathrm{C}$, respectively. The GC interface temperature was $200^{\circ} \mathrm{C}$. The injector was fitted with a 2-mm i.d. liner in splitless mode.

\section{Peak identification and quantification.}

GC-MS chromatograms were analyzed using TurboMass software (version 6.1; Perkin Elmer). Peaks were first identified by comparing their mass spectra with library entries of NIST 2011 (National Institute of Standards and Technology, Gaithersburg, MA, U.S.A.) and Wiley, 9th edition (John Wiley and Sons, Inc., Hoboken, NJ, U.S.A.). Identification of AA, $\mathrm{OA}$, and FA was further confirmed by comparing their retention time, linear retention indices, and mass spectra with authentic standards. Compound peak areas were normalized to the internal standard (heptadecanoic acid). Quantification of leaf metabolites was based on the peak areas obtained from a series of reference standards derivatized and injected under the same conditions as the samples (Supplementary Table S1). Calibration curves were constructed from the linear regressions 
obtained by plotting the concentration versus peak area for each standard.

\section{Gene expression analysis using quantitative real-time PCR.}

TriZol reagent (Ambion, Life Technologies, Carlsbad, CA, U.S.A.) was used to extract total RNA from samples. The quantity and quality of isolated RNA were assessed using a NanoDrop 2000 spectrophotometer (Thermo Scientific, U.S.A.). The SuperScript first-strand synthesis system (Invitrogen, Carlsbad, CA, U.S.A.) with random hexamer primers, as described by the manufacturer's instructions, was used to synthesize cDNA. SYBR Green PCR master mix (Applied Biosystems) was used to perform the quantitative PCR on an ABI 7500 Fast-Time PCR System (Applied Biosystems). Samples were analyzed in triplicate for each biological replicate for each treatment. Primers for 21 various genes were used to measure the gene expression (Supplementary Table S2). The relative expression of the consensus sequence among PCR products was done according to the $2^{-\Delta \Delta C}$ method (Livak and Schmittgen 2001). Normalization of gene expression was performed using four endogenous genes (reference genes), including EF1, F-box, GAPDH, and SAND (Mafra et al. 2012; Wei et al. 2014a and b).

\section{Statistical analysis.}

All compound concentrations were statistically analyzed according to the analysis of variance technique. Post hoc pairwise comparisons between the four studied treatments were performed with the Tukey-Kramer honestly significant different test. PCA was performed and the associated loading plots were generated using the concentrations of detected metabolites. Two-way HCA was performed using the average of each metabolite in each treatment. Distance and linkage were done using the Ward method (Ward 1963), and multivariate gene similarities were presented as a heat map. Three-dimensional surface plots were performed with the data of the matrices for the four studied treatments.

\section{ACKNOWLEDGMENTS}

We thank S. Jones and L. Lindsey for their assistance with the psyllid colonies, C. I. Vincent and S. E. Jones for help with the English editing, and F. Hijaz for the technical assistance in GC-MS. This work was funded by the Citrus Initiative program, University of Florida.

\section{LITERATURE CITED}

Bari, R., and Jones, J. D. G. 2009. Role of plant hormones in plant defence responses. Plant Mol. Biol. 69:473-488.

Bennett, R. N., and Wallsgrove, R. M. 1994. Secondary metabolites in plant defence mechanisms. New Phytol. 127:617-633.

Bernsdorff, F., Döring, A.-C., Gruner, K., Schuck, S., Bräutigam, A., and Zeier, J. 2016. Pipecolic acid orchestrates plant systemic acquired resistance and defense priming via salicylic acid-dependent and -independent pathways. Plant Cell 28:102-129.

Boggess, S. F. 1976. Contribution of arginine to proline accumulation in water-stressed barley leaves. Plant Physiol. 58:796-797.

Bolton, M. D. 2009. Primary metabolism and plant defense-fuel for the fire. Mol. Plant-Microbe Interact. 22:487-97.

Bové, J. M. 2006. Huanglongbing: A destructive, newly-emerging, centuryold disease of citrus. J. Plant Pathol. 88:7-37.

Bové, J. M., and Ayres, A. J. 2007. Etiology of three recent diseases of citrus in São Paulo State: Sudden death, variegated chlorosis and huanglongbing. IUBMB Life 59:346-354.

Buckner, J. S., and Hagen, M. M. 2003. Triacylglycerol and phospholipid fatty acids of the silverleaf whitefly: Composition and biosynthesis. Arch. Insect Biochem. Physiol. 53:66-79.

Cevallos-Cevallos, J. M., Futch, D. B., Shilts, T., Folimonova, S. Y., and Reyes-De-Corcuera, J. I. 2012. GC-MS metabolomic differentiation of selected citrus varieties with different sensitivity to citrus huanglongbing. Plant Physiol. Biochem. 53:69-76.
Cevallos-Cevallos, J. M., García-Torres, R., Etxeberria, E., and Reyes-DeCorcuera, J. I. 2011. GC-MS analysis of headspace and liquid extracts for metabolomic differentiation of citrus huanglongbing and zinc deficiency in leaves of "Valencia" sweet orange from commercial groves. Phytochem. Anal. 22:236-246.

Chen, L. S., Tang, N., Jiang, H. X., Yang, L. T., Li, Q., and Smith, B. R. 2009. Changes in organic acid metabolism differ between roots and leaves of Citrus grandis in response to phosphorus and aluminum interactions. J. Plant Physiol. 166:2023-2034.

Chen, Z., Zheng, Z., Huang, J., Lai, Z., and Fan, B. 2009. Biosynthesis of salicylic acid in plants. Plant Signal. Behav. 4:493-496.

Chin, E. L., Mishchuk, D. O., Breksa, A. P., and Slupsky, C. M. 2014 Metabolite signature of Candidatus Liberibacter asiaticus infection in two citrus varieties. J. Agric. Food Chem. 62:6585-6591.

Coquoz, J.-L., Buchala, A., and Métraux, J.-P. 1998. The biosynthesis of salicylic acid in potato plants. Plant Physiol. 117:1095-1101.

da Graça, J. V. 1991. Citrus greening disease. Annu. Rev. Phytopathol. 29: 109-136.

da Graça, J. V., and Korsten, L. 2004. Citrus huanglongbing: Review, present status and future strategies. Pages 229-245 in: Diseases of Fruits and Vegetables, Vol. I. S. A. M. H. Naqvi, ed. Springer Science+Business Media B.V., Dordrecht, The Netherlands.

del Río-Celestino, M., Font, R., and de Haro-Bailón, A. 2008. Distribution of fatty acids in edible organs and seed fractions of borage (Borago officinalis L.). J. Sci. Food Agric. 88:248-255.

Dong, C.-J., Li, L., Shang, Q.-M., Liu, X.-Y., and Zhang, Z.-G. 2014. Endogenous salicylic acid accumulation is required for chilling tolerance in cucumber (Cucumis sativus L.) seedlings. Planta 240:687-700.

Douglas, A. E. 1993. The nutritional quality of phloem sap utilized by natural aphid populations. Ecol. Entomol. 18:31-38.

Duan, Y., Zhou, L., Hall, D. G., Li, W., Doddapaneni, H., Lin, H., Liu, L. Vahling, C. M., Gabriel, D. W., Williams, K. P., Dickerman, A., Sun, Y., and Gottwald, T. 2009. Complete genome sequence of citrus huanglongbing bacterium, "Candidatus Liberibacter asiaticus" obtained through metagenomics. Mol. Plant-Microbe Interact. 22:1011-1020.

Durrant, W. E., and Dong, X. 2004. Systemic acquired resistance. Annu. Rev. Phytopathol. 42:185-209.

Erb, M., Meldau, S., and Howe, G. A. 2012. Role of phytohormones in insect-specific plant reactions. Trends Plant Sci. 17:250-259.

Fan, J., Chen, C., Yu, Q., Brlansky, R. H., Li, Z.-G., and Gmitter, F. G. 2011. Comparative iTRAQ proteome and transcriptome analyses of sweet orange infected by "Candidatus Liberibacter asiaticus". Physiol. Plant. 143:235-245.

Farmer, E. E., and Ryan, C. A. 1992. Octadecanoid precursors of jasmonic acid activate the synthesis of wound-inducible proteinase inhibitors Plant Cell 4:129-134.

Folimonova, S. Y., Robertson, C. J., Garnsey, S. M., Gowda, S., and Dawson, W. O. 2009. Examination of the responses of different genotypes of citrus to huanglongbing (citrus greening) under different conditions. Phytopathology 99:1346-1354.

Forest, J. C., and Wightman, F. 1972. Amino acid metabolism in plants. III. Purification and some properties of a multispecific aminotransferase isolated from bushbean seedlings (Phaseolus vulgaris L.). Can. J. Biochem. 50:813-829.

Fu, Z. Q., and Dong, X. 2013. Systemic acquired resistance: Turning local infection into global defense. Annu. Rev. Plant Biol. 64:839-863.

Glazebrook, J. 2005. Contrasting mechanisms of defense against biotrophic and necrotrophic pathogens. Annu. Rev. Phytopathol. 43:205-227.

Gottwald, T. R. 2010. Current epidemiological understanding of citrus huanglongbing. Annu. Rev. Phytopathol. 48:119-39.

Gottwald, T. R., Aubert, B., and Zhao, X.-Y. 1989. Preliminary analysis of citrus greening (huanglungbin) epidemics in the People's Republic of China and French Reunion Island. Phytopathology 79:687-693.

Guidetti-Gonzalez, S., Freitas-Astúa, J., do Amaral, A. M., Martins, N. F., Mehta, A., Silva, M. S., and Carrer, H. 2007. Genes associated with hypersensitive response (HR) in the citrus EST database (CitEST). Genet. Mol. Biol. 30:943-956.

Halbert, S. E., and Manjunath, K. L. 2004. Asian citrus psyllids (Sternorrhyncha: Psyllidae) and greening disease of citrus: A literature review and assessment of risk in Florida. Fla. Entomol. 87:330-353.

Hatcher, P. E., Moore, J., Taylor, J. E., Tinney, G. W., and Paul, N. D. 2004. Phytohormones and plant-herbivore-pathogen interactions: Integrating the molecular with the ecological. Ecology 85:59-69.

Hijaz, F., and Killiny, N. 2014. Collection and chemical composition of phloem sap from Citrus sinensis L. Osbeck (sweet orange). PLoS One 9:e101830.

Kachroo, A., Lapchyk, L., Fukushige, H., Hildebrand, D., Klessig, D., and Kachroo, P. 2003. Plastidial fatty acid signaling modulates salicylic acid- 
and jasmonic acid-mediated defense pathways in the Arabidopsis ssi2 mutant. Plant Cell 15:2952-2965.

Kangasjärvi, S., Neukermans, J., Li, S., Aro, E.-M., and Noctor, G. 2012. Photosynthesis, photorespiration, and light signalling in defence responses. J. Exp. Bot. 63:1619-1636.

Kombrink, E., and Schmelzer, E. 2001. The hypersensitive response and its role in local and systemic disease resistance. Eur. J. Plant Pathol. 107:69-78.

Kushalappa, A. C., and Gunnaiah, R. 2013. Metabolo-proteomics to discover plant biotic stress resistance genes. Trends Plant Sci. 18:522-531.

Lazebnik, J., Frago, E., Dicke, M., and van Loon, J. J. A. 2014 Phytohormone mediation of interactions between herbivores and plant pathogens. J. Chem. Ecol. 40:730-741.

Liechti, R., Gfeller, A., and Farmer, E. E. 2006. Jasmonate signaling pathway. Sci. Signaling 2006: $\mathrm{cm} 2$.

Lin, K.-H. 1956. Observations on yellow shoot of citrus. Etiological studies of yellow shoot of citrus. Acta Phytopathol. Sin. 2:1-42.

Liu, H., Wang, X., Zhang, H., Yang, Y., Ge, X., and Song, F. 2008. A rice serine carboxypeptidase-like gene $O S B I S C P L 1$ is involved in regulation of defense responses against biotic and oxidative stress. Gene 420:57-65.

Livak, K. J., and Schmittgen, T. D. 2001. Analysis of relative gene expression data using real-time quantitative PCR and the $2^{-\Delta \Delta C}$ method. Methods 25:402-408.

Macarisin, D., Cohen, L., Eick, A., Rafael, G., Belausov, E., Wisniewski, M., and Droby, S. 2007. Penicillium digitatum suppresses production of hydrogen peroxide in host tissue during infection of citrus fruit. Phytopathology 97:1491-1500.

Mafra, V., Kubo, K. S., Alves-Ferreira, M., Ribeiro-Alves, M., Stuart, R. M., Boava, L. P., Rodrigues, C. M., and Machado, M. A. 2012. Reference genes for accurate transcript normalization in citrus genotypes under different experimental conditions. PLoS One 7:e31263.

Malik, N. S. A. 1982. Senescence in Detached oat leaves I. Changes in free amino acid levels. Plant Cell Physiol. 23:49-57.

Malik, N. S. A., Perez, J. L., Kunta, M., Patt, J. M., and Mangan, R. L. 2014. Changes in free amino acids and polyamine levels in Satsuma leaves in response to Asian citrus psyllid infestation and water stress. Insect Sci. 21:707-716.

Matthews, B. F., and Hughes, C. A. 1993. Nutritional improvement of the aspartate family of amino acids in edible crop plants. Amino Acids 4:21-34

Mugford, S. T., Qi, X., Bakht, S., Hill, L., Wegel, E., Hughes, R. K., Papadopoulou, K., Melton, R., Philo, M., Sainsbury, F., Lomonossoff, G. P., Roy, A. D., Goss, R. J. M., and Osbourn, A. 2009. A serine carboxypeptidase-like acyltransferase is required for synthesis of antimicrobial compounds and disease resistance in oats. Plant Cell 21: 2473-2484.

Rivas, F., Fornes, F., and Agustí, M. 2008. Girdling induces oxidative damage and triggers enzymatic and non-enzymatic antioxidative defences in citrus leaves. Environ. Exp. Bot. 64:256-263.

Robert-Seilaniantz, A., Navarro, L., Bari, R., and Jones, J. D. 2007. Pathological hormone imbalances. Curr. Opin. Plant Biol. 10:372-379.

Rojas, C. M., Senthil-Kumar, M., Tzin, V., and Mysore, K. S. 2014. Regulation of primary plant metabolism during plant-pathogen interactions and its contribution to plant defense. Front. Plant Sci. 5:17.

Seo, J.-K., Wu, J., Lii, Y., Li, Y., and Jin, H. 2013. Contribution of small RNA pathway components in plant immunity. Mol. Plant-Microbe Interact. 26:617-625.

Shivaji, R., Camas, A., Ankala, A., Engelberth, J., Tumlinson, J. H., Williams, W. P., Wilkinson, J. R., and Luthe, D. S. 2010. Plants on constant alert: Elevated levels of jasmonic acid and jasmonate-induced transcripts in caterpillar-resistant maize. J. Chem. Ecol. 36:179-191.

Slisz, A. M., Breksa, A. P., Mishchuk, D. O., McCollum, G., and Slupsky, C. M. 2012. Metabolomic analysis of citrus infection by "Candidatus Liberibacter" reveals insight into pathogenicity. J. Proteome Res. 11: 4223-4230.

Song, J. T., Lu, H., McDowell, J. M., and Greenberg, J. T. 2004. A key role for ALD1 in activation of local and systemic defenses in Arabidopsis. Plant J. 40:200-212.
Stipanuk, M. H. 2006. Biochemical, Physiological, and Molecular Aspects of Human Nutrition, 2nd ed. Saunders Elsevier, Philadelphia, PA, U.S.A.

Tatineni, S., Sagaram, U. S., Gowda, S., Robertson, C. J., Dawson, W. O., Iwanami, T., and Wang, N. 2008. In planta distribution of 'Candidatus Liberibacter asiaticus' as revealed by polymerase chain reaction (PCR) and real-time PCR. Phytopathology 98:592-599.

Tomlin, E. S., and Sears, M. K. 1992. Effects of Colorado potato beetle and potato leafhopper on amino acid profile of potato foliage. J. Chem. Ecol. 18:481-488.

Tooker, J. F., and De Moraes, C. M. 2009. A gall-inducing caterpillar species increases essential fatty acid content of its host plant without concomitant increases in phytohormone levels. Mol. Plant-Microbe Interact. 22:551-559.

Wallis, C. M., Chen, J., and Civerolo, E. L. 2012. Zebra chip-diseased potato tubers are characterized by increased levels of host phenolics, amino acids, and defense-related proteins. Physiol. Mol. Plant Pathol. 78:66-72.

Wallis, C. M., Rashed, A., Chen, J., Paetzold, L., Workneh, F., and Rush, C. M. 2015. Effects of potato-psyllid-vectored 'Candidatus Liberibacter solanacearum' infection on potato leaf and stem physiology. Phytopathology 105:189-198.

Wallis, C. M., Rashed, A., Wallingford, A. K., Paetzold, L., Workneh, F., and Rush, C. M. 2014. Similarities and differences in physiological responses to "Candidatus Liberibacter solanacearum" infection among different potato cultivars. Phytopathology 104:126-133.

Wang, N., and Trivedi, P. 2013. Citrus huanglongbing: A newly relevant disease presents unprecedented challenges. Phytopathology 103:652-665.

War, A. R., Paulraj, M. G., Ahmad, T., Buhroo, A. A., Hussain, B., Ignacimuthu, S., and Sharma, H. C. 2012. Mechanisms of plant defense against insect herbivores. Plant Signal. Behav. 7:1306-1320.

Ward, J. H. 1963. Hierarchical grouping to optimize an objective function. J. Am. Stat. Assoc. 58:236-244.

Wasternack, C., and Hause, B. 2013. Jasmonates: Biosynthesis, perception, signal transduction and action in plant stress response, growth and development. An update to the 2007 review in Annals of Botany. Ann. Bot. (Lond.) 111:1021-1058.

Wei, X., Chen, C., Yu, Q., Gady, A., Yu, Y., Liang, G., and Gmitter, F. G. 2014a. Comparison of carotenoid accumulation and biosynthetic gene expression between Valencia and Rohde Red Valencia sweet oranges. Plant Sci. 227:28-36

Wei, X., Chen, C., Yu, Q., Gady, A., Yu, Y., Liang, G., and Gmitter, F. G. 2014b. Novel expression patterns of carotenoid pathway-related genes in citrus leaves and maturing fruits. Tree Genet. Genomes 10:439-448.

Yang, H., and Ludewig, U. 2014. Lysine catabolism, amino acid transport, and systemic acquired resistance What is the link? Plant Signal. Behav. 9: Article e28933.

Yang, X.-B., Malik, N. S. A., Perez, J. L., and Liu, T.-X. 2011. Impact of potato psyllid (Hemiptera: Triozidae) feeding on free amino acid composition in potato. Insect Sci. 18:663-670.

Zeier, J. 2013. New insights into the regulation of plant immunity by amino acid metabolic pathways. Plant Cell Environ. 36:2085-2103.

Zhang, S., Li, X., Sun, Z., Shao, S., Hu, L., Ye, M., Zhou, Y., Xia, X., Yu, J., and Shi, K. 2015. Antagonism between phytohormone signalling underlies the variation in disease susceptibility of tomato plants under elevated $\mathrm{CO}_{2}$. J. Exp. Bot. 66:1951-1963.

Zhao, H., Sun, R., Albrecht, U., Padmanabhan, C., Wang, A., Coffey, M. D., Girke, T., Wang, Z., Close, T. J., Roose, M., Yokomi, R. K., Folimonova, S., Vidalakis, G., Rouse, R., Bowman, K. D., and Jin, H. 2013. Small RNA profiling reveals phosphorus deficiency as a contributing factor in symptom expression for citrus huanglongbing disease. Mol. Plant 6: 301-310.

Zhao, J., Davis, L. C., and Verpoorte, R. 2005. Elicitor signal transduction leading to production of plant secondary metabolites. Biotechnol. Adv. 23:283-333.

Zhu, L., Chen, M.-S., and Liu, X. 2011. Changes in phytohormones and fatty acids in wheat and rice seedlings in response to Hessian fly (Diptera: Cecidomyiidae) infestation. J. Econ. Entomol. 104:1384-1392. 